\title{
Airframe Noise from a Hybrid Wing Body Aircraft Configuration
}

\author{
Florence V. Hutcheson ${ }^{1}$, Taylor B. Spalt ${ }^{2}$, Thomas F. Brooks ${ }^{3}$ \\ NASA Langley Research Center, Hampton, VA \\ and \\ Gerald E. Plassman ${ }^{4}$ \\ National Institute of Aerospace, Hampton, VA
}

\begin{abstract}
A high fidelity aeroacoustic test was conducted in the NASA Langley 14- by 22-Foot Subsonic Tunnel to establish a detailed database of component noise for a $5.8 \%$ scale HWB aircraft configuration. The model has a modular design, which includes a drooped and a stowed wing leading edge, deflectable elevons, twin verticals, and a landing gear system with geometrically scaled wheel-wells. The model is mounted inverted in the test section and noise measurements are acquired at different streamwise stations from an overhead microphone phased array and from overhead and sideline microphones. Noise source distribution maps and component noise spectra are presented for airframe configurations representing two different approach flight conditions. Array measurements performed along the aircraft flyover line show the main landing gear to be the dominant contributor to the total airframe noise, followed by the nose gear, the inboard side-edges of the LE droop, the wing tip/LE droop outboard side-edges, and the side-edges of deployed elevons. Velocity dependence and flyover directivity are presented for the main noise components. Decorrelation effects from turbulence scattering on spectral levels measured with the microphone phased array are discussed. Finally, noise directivity maps obtained from the overhead and sideline microphone measurements for the landing gear system are provided for a broad range of observer locations.
\end{abstract}

\section{Introduction}

A high fidelity aeroacoustic test was performed in the 14- by 22-Foot Subsonic Tunnel facility at the NASA Langley Research Center to evaluate a proposed "low noise" Hybrid Wing Body (HWB) aircraft configuration called N2A-EXTE. This HWB aircraft concept was designed by a team led by Boeing under a NASA Research Announcement $^{1}$ (NRA). The Boeing team included partners from the University of California Irvine, the Massachusetts Institute of Technology and the United Technology Research Center. A primary objective of this NRA was to design an HWB configuration capable of meeting the NASA N+2 noise goal of cumulative Effective Perceived Noise Level (EPNL) noise margin of $42 \mathrm{~dB}$ relative to FAR 36 Stage 4, as well as meet fuel efficiency goals ${ }^{2}$. The culmination of this NRA was the delivery of a 5.8-percent scale model of the N2A-EXTE for aerodynamic ${ }^{3}$ and aeroacoustic testing in the 14- by 22-Foot Subsonic Tunnel. The purpose of the aeroacoustic test was to establish a detailed database of the N2A-EXTE noise components that could be used to perform system level noise assessments of the N2A-EXTE and of other unconventional aircraft configurations. The system noise assessment of the N2AEXTE vehicle was performed using the test data in combination with ANOPP2 (the NASA's Aircraft Noise Prediction Program2) predictions. The results from this assessment and a comparison to the NASA N+2 noise goal are reported in Reference 4.

\footnotetext{
${ }^{1}$ Senior Research Engineer, Aeroacoustics Branch, Senior Member AIAA.

${ }^{2}$ Research Engineer (formerly), Aeroacoustics Branch, Member AIAA.

${ }^{3}$ Senior Research Scientist (Retired), Aeroacoustics Branch, Fellow AIAA.

${ }^{4}$ Associate Principal Engineer, Senior Member AIAA.
} 
The aeroacoustic test was conducted in three parts ${ }^{5}$. In the first part, the effects of engine placement, vertical tail configuration, and flight condition on the shielding of the broadband component of turbomachinery noise were investigated. In the second part (focus of the present paper), the spectra and directivity of the noise radiating from different components of the airframe were examined. Finally, in the third part of the test, jet noise (from both axisymmetric nozzles and low noise chevron nozzles) and its shielding by the airframe were investigated for different operating conditions. Results from the first and third test segments are presented in References 6 and 7, respectively, while the results from the airframe noise portion of the test are presented in this paper.

Descriptions of the airframe noise test set-up and of the N2A-EXTE model are presented in Section 2. The data acquisition and processing are discussed in Section 3. In Section 4, the test results are examined. These results include airframe component directivities and spectra from microphone phased array measurements in the flyover plane for two different airframe configurations, sideline and flyover directivities of the landing gear system from microphones distributed around the test section, a comparison of landing gear noise levels obtained from single microphone measurements with those obtained from the microphone phased array, and effects of flow Mach number on component noise. The paper concludes with a summary of the results in Section 5.

\section{Test Set-Up}

A picture of the test set-up is shown in Fig. 1. The wind tunnel test section was configured for acoustic testing ${ }^{8}$, with side walls removed and ceiling raised above the flow shear layer. The test section floor was designed to provide a streamlined surface for the wind tunnel flow while maintaining good acoustic absorption. Surfaces away from the tunnel flow were covered with acoustic treatment. A full-span wind tunnel model of the N2A-EXTE HWB aircraft was positioned inverted in the test section, with its center of gravity located approximately 18.5 feet downstream of the wind tunnel nozzle exit. An overhead-traversing microphone phased array ${ }^{9}$, as well as overhead- and sidelinetraversing microphones, was positioned outside of the test section flow and used to perform the acoustic measurements. A detailed description of the hardware used is provided in Reference 9.

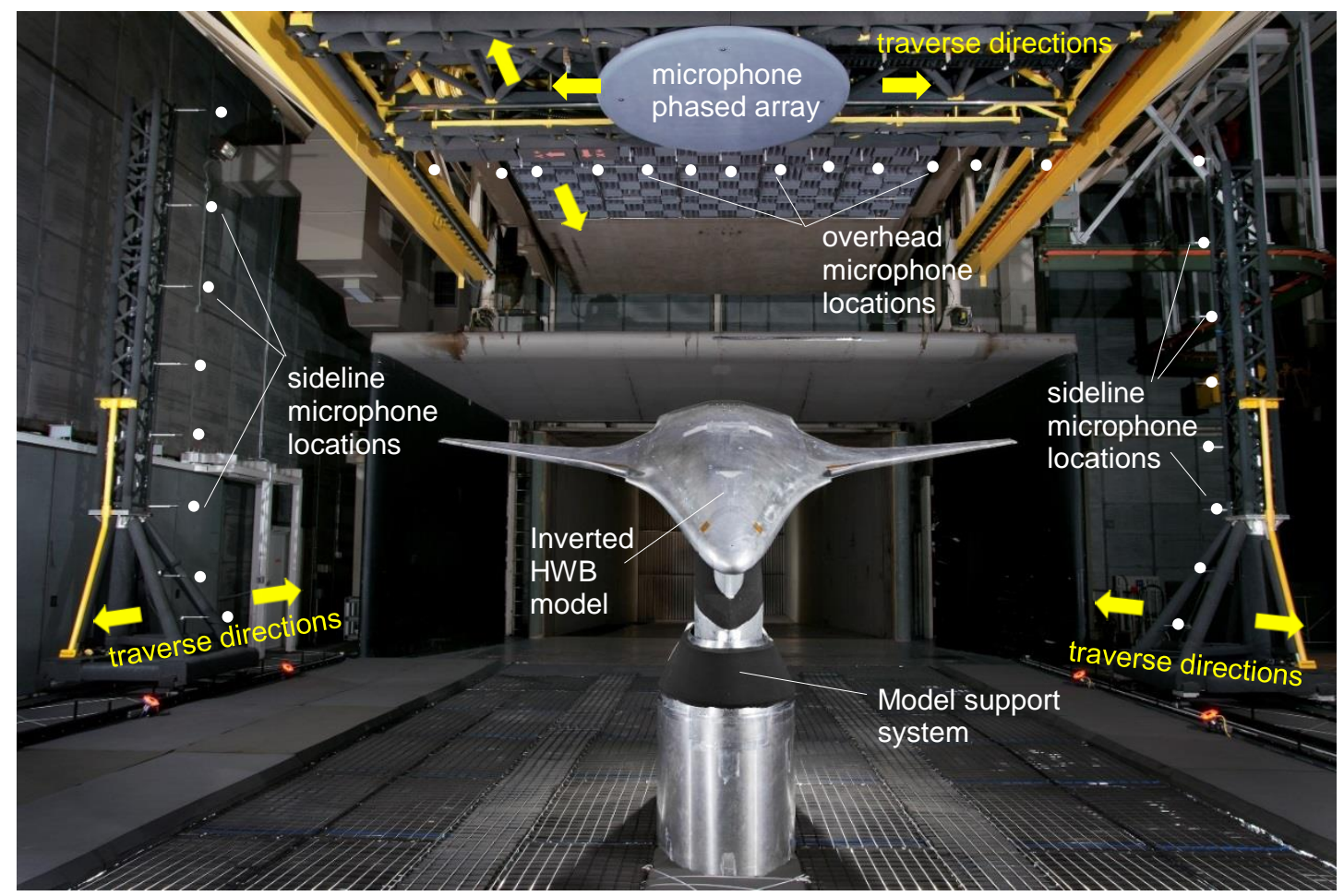

Figure 1. Test set-up inside the open test section of the Langley 14- by 22-Foot Subsonic Tunnel

The overhead- and sideline-traversing microphones consisted of twenty-nine 1/8-inch pressure-field microphones distributed around the test section. These microphones were used to obtain hemispherical characterizations of noise directivity for the different model configurations tested. They were spaced nominally at $7.5^{\circ}$ increments about the center of the test model and were traversed together with the microphone phased array to predefined streamwise stations. The microphone phased array was mounted on a two-directional traverse approximately 13 feet above the inverted model to perform noise measurement along the "flyover line" up to $45^{\circ}$ upstream and downstream of the 
model. The array was installed in the same plane as the overhead-traversing microphones with its center positioned approximately 62 inches upstream of the overhead microphones. The array was populated with 97 1/4-inch pressurefield microphones, which were flush mounted in a flat, fiberglass panel. The array panel has an 8.05-foot diameter, with a maximum distance between microphones of 6.55 feet, yielding a solid collecting angle of $29.4^{\circ}$ at a distance of 12.5 feet. The operational frequency range of the array is $1.5 \mathrm{kHz}$ to $80 \mathrm{kHz}^{9}$.

HWB model:

The wind tunnel model was fabricated to 5.8\% (12.35 foot span) of full scale. The test model scale, which was determined by the wind tunnel size and microphone frequency limitations, allowed for acoustic measurements to be performed over the full-scale equivalent range of $230 \mathrm{~Hz}$ to $4.1 \mathrm{kHz}$ (nominally $4 \mathrm{kHz}$ to $70 \mathrm{kHz}$, model-scale) that is critical to aircraft noise assessment. The test model (depicted in Fig. 2) had a modular design. It consisted of a fixed blended centerbody/wing to which various components such as control surfaces and landing gear were attached. The control surface components included a drooped and a stowed leading edge to model high lift and cruise or "clean" wing configurations, twelve elevons that were deflected along the wing trailing edge to match specific flight conditions, and twin verticals of two different sizes and cant (dihedral) angles with forward and aft fuselage positions for the engine noise shielding study. One pair of the verticals had manually deflectable rudders. The landing gear system included a nose and two main gear (shown in Fig. 3a). All gear components, hydraulic lines, actuators, side braces, brake system and tire treads were accurately scaled. Attention to the fidelity of the landing gear geometric details and of the control surfaces' trailing edges was emphasized during the manufacturing process to ensure the accuracy of the noise measured from these components. The nose and main landing gear were mounted on the model in geometrically scaled wheel-wells, as shown in Fig. 3 b.

(a)

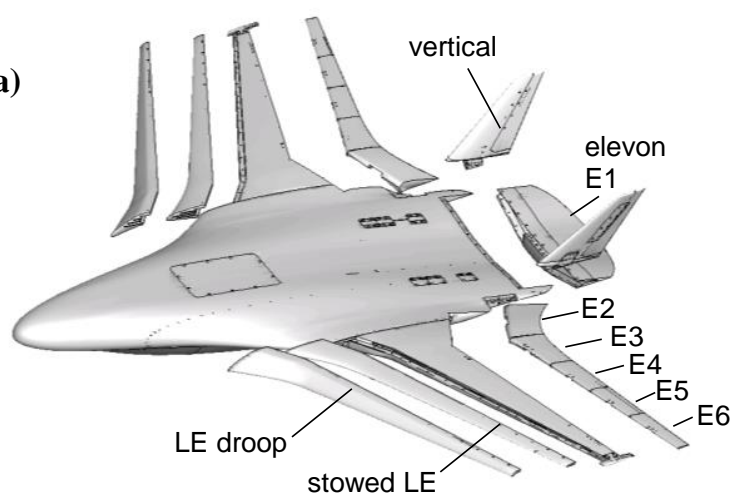

(b)

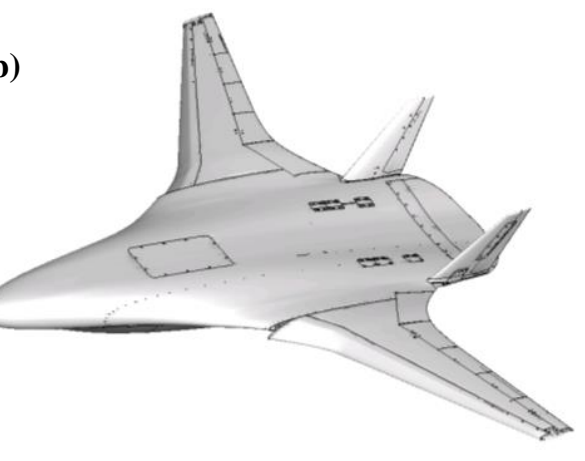

Figure 2. N2A-EXTE HWB model (upper side shown); (a) modular component breakdown; (b) assembled (LE droop, elevons undeflected, verticals with $10^{\circ}$ outward cant).

(a)

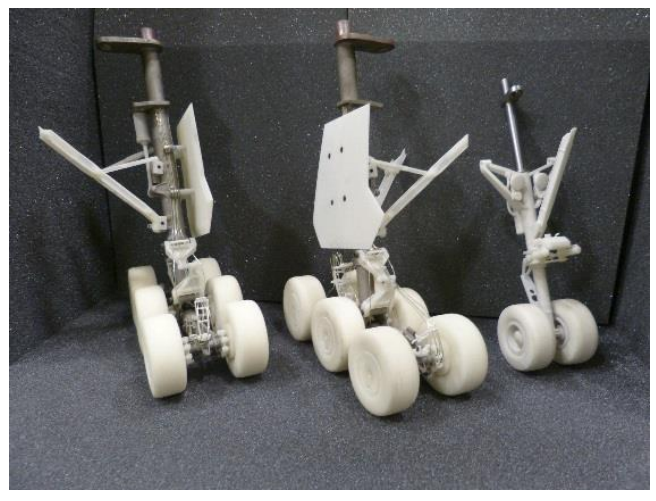

(b)

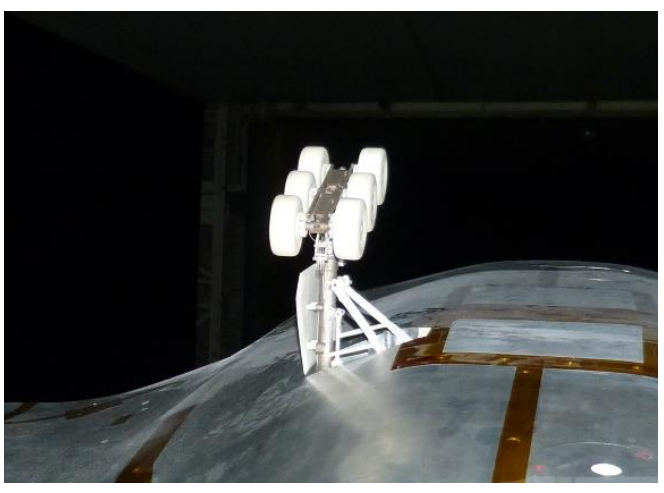

Figure 3. (a) High fidelity models of the nose and two main landing gear; (b) Port-side main landing gear installed in geometrically scaled gear well. 


\section{Data Acquisition and Processing}

Transient data recorders controlled by a workstation were used to simultaneously acquire the data from the array, sideline and overhead microphone channels at a sampling rate of $250 \mathrm{kHz}$. Low-pass and high-pass filters set at 102.4 $\mathrm{kHz}$ and $400 \mathrm{~Hz}$, respectively, were used to condition the outputs from each microphone channel. Cross-spectral matrices were constructed for each set of data acquired from the microphone phased array while auto-spectra were computed for each set of data acquired from the overhead and sideline microphones. The time history signals were partitioned into non-overlapping segments of $2^{13}$ samples. Each segment was then Fourier transformed using a Hamming window. The resulting frequency resolution was $30.5 \mathrm{~Hz}$. Shear layer refraction ${ }^{10}$, microphone directivity and atmospheric attenuation corrections were applied. Final emission corrections assumed a noise source located midway between the two main landing gear and level with the mid-length of the main struts. This location also represents the origin of the coordinate system used in this analysis to define observer locations in terms of polar and azimuthal emission angles. Additional processing of the time series was performed to remove signal contamination from transient hydrodynamic gusts induced by the proximity of the open-jet shear layer to the microphones. The methodology employed to perform the corrections listed above is discussed in Reference 11, while the procedures used to calibrate the array, overhead and sideline microphones are detailed in Reference 9.

\subsection{Microphone phased array data}

The microphone phased array data were processed using conventional frequency-domain delay and sum beamforming together with the DAMAS ${ }^{12}$ deconvolution algorithm to obtain spatial mapping of the noise sources on the N2A-EXTE model for different airframe configurations. Prior to beamforming and DAMAS processing, background subtraction was performed to reduce contamination from extraneous noise sources and to better isolate noise sources of interest. For this, the cross-spectral matrices obtained from the data acquired with and without the noise source(s) of interest were subtracted vectorially. The scanning grid used for the DAMAS processing was a 224by 224-inch planar grid parallel to the model waterline and approximately positioned through the wing tips of the HWB model. No diagonal removal or conditioning ${ }^{13}$ of the cross spectral matrices was performed in the DAMAS processing procedure. Microphone weighting ${ }^{9}$ was applied to ensure a frequency-independent beamwidth of approximately 6 inches over the frequency range of interest. DAMAS maps for each narrowband ( 7 adjacent bins combined) frequency were generated and then summed on a pressure-squared basis to obtain the one-third octave band maps presented in Section 4. Maps were generated over a one-third octave band frequency range of $1.6 \mathrm{kHz}$ to $40 \mathrm{kHz}$ (model scale). Spectra of the noise radiating from particular regions of the model were obtained from the DAMAS maps produced for each one-third octave band. The spectral level for a given one-third octave frequency band was obtained by summing the mean-squared pressures over the region of interest.

\subsection{Overhead and sideline microphone data}

The overhead and sideline microphones were used to obtain additional noise directivity characteristics for specific model components. Acoustic measurements of the noise radiating from the model with and without the component of interest installed were acquired at different overhead and sideline microphone streamwise stations. The two resulting sets of measurements were then subtracted from each other (on an acoustic pressure-squared basis) to obtain a measure of the noise radiating from the component of interest over a broad range of observer locations.

\section{Experimental Results}

\subsection{Microphone phased array measurements}

The N2A-EXTE noise source distribution maps and component noise spectra obtained from microphone phased array measurements are presented in this section. These noise measurements were performed for model configurations corresponding to two specific approach flight conditions ${ }^{4}$. A small subset of measurements were also acquired to examine elevon noise.

\section{Approach flight configurations A1 and A2}

The model airframe configurations corresponding to the two approach flight conditions examined are referred to as A1 and A2, respectively. Configurations A1 and A2 only differ by their elevon settings and angle of attack (AOA) with respect to the freestream flow. For A1, the model was positioned in the wind tunnel at $13.1^{\circ} \mathrm{AOA}$ with all elevons at $0^{\circ}$ deployment angle. For A2, the model was positioned at $15.5^{\circ}$ AOA with elevons E1 through E4 (see Fig.2) deployed at $-10^{\circ}$ (i.e., up, towards the model suction side) and elevons E5 and E6 undeflected. For both A1 and A2, the model is configured with Leading Edge (LE) droop, narrow twin verticals (with a $10^{\circ}$ outward cant) and landing gear system deployed. Airframe noise measurements for these two model configurations were acquired at a flow Mach number of 0.17, as well as at Mach 0.19 for A1 and Mach 0.21 for A2. The latter two Mach numbers correspond, respectively, to the design speeds of the A1 and A2 approach flight conditions. 
Noise source distribution maps and component noise spectra obtained for A1 and A2 are presented below. Data shown were obtained from measurements performed with the microphone phased array in the model flyover plane at streamwise stations $\mathrm{X}=6.4,11.75,16.4$ and 21.75 feet, where $\mathrm{X}$ is measured from the wind tunnel nozzle exit. The background cross-spectral matrices used in the processing of the microphone phased array data were obtained from measurements performed with the N2A-EXTE model in a "clean" configuration (i.e., with the landing gear system and wing leading edge stowed, elevons undeflected, the verticals removed and the airframe at $0^{\circ} \mathrm{AOA}$ ). This background noise subtraction was performed to better isolate noise from the LE droop, landing gear system, elevons (when deflected) and verticals of the A1 and A2 airframe configurations.

\section{A1 noise source distribution maps}

A sample of noise source distribution maps generated for the A1 configuration is displayed in Fig. 4. The flow Mach number is 0.17 and the AOA of the model is $13.1^{\circ}$. The microphone phased array is located above the model at streamwise station: $X=16.4$ feet. This corresponds to a polar (flyover) emission angle, $\theta$, of $87.6^{\circ}$, where $\theta$ is measured relative to the longitudinal axis of the N2A-EXTE model with $\theta=0^{\circ}$ at the nose and $\theta=90^{\circ}$ underneath the model. The underside of the N2A-EXTE and of the landing gear trucks is shown in each map. These maps reveal noise sources at the nose and main landing gear locations, at the LE droop inboard side-edges, and at the wing tips (and/or LE droop outboard side-edges, as these edges are nearly co-located with the wing tips). Close-up views of the LE droop sideedges are shown in Fig. 5. Note that for simplicity, in the rest of this paper, noise from the LE droop inboard and outboard side-edges will be referred to as droop-inboard noise and droop-outboard noise, respectively.

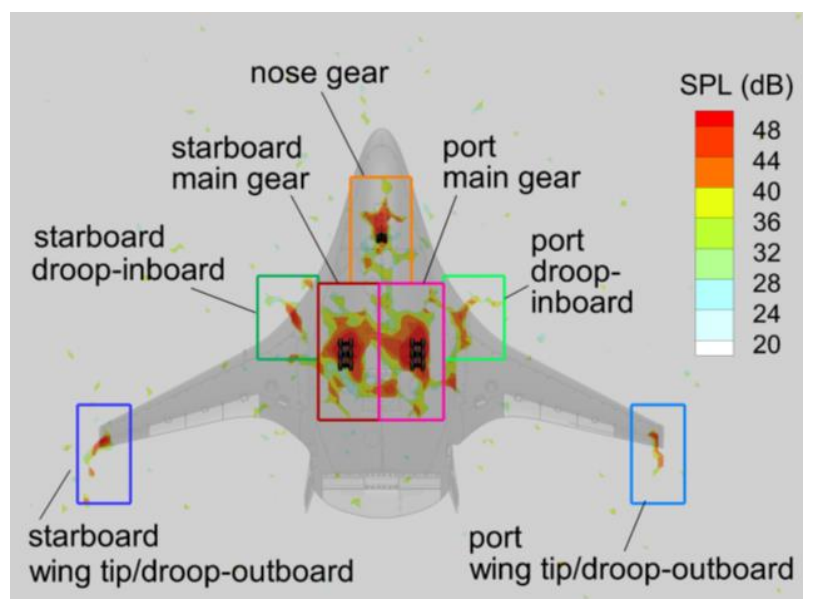

(a) $3.15 \mathrm{kHz}$

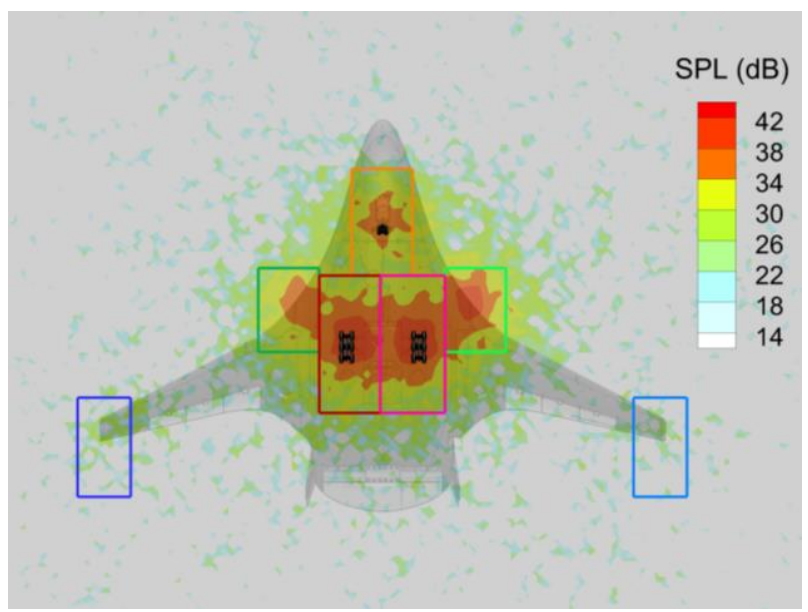

(c) $12.5 \mathrm{kHz}$

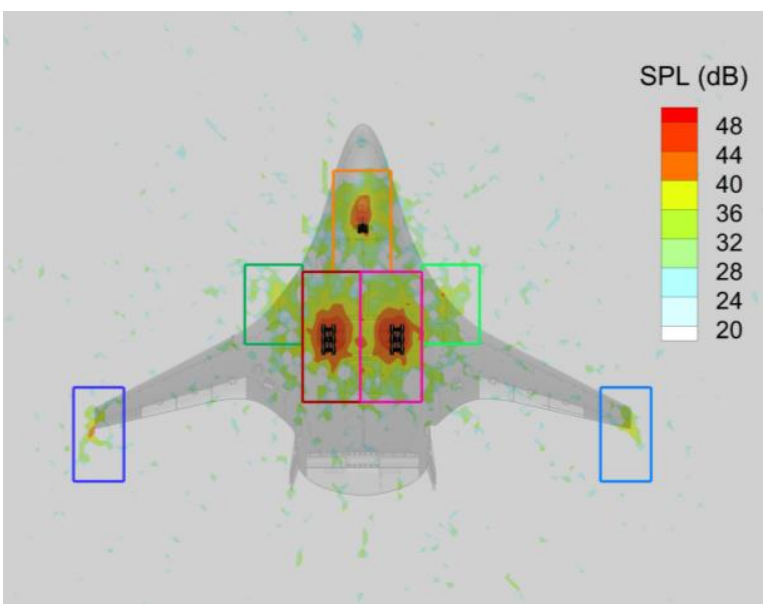

(b) $6.3 \mathrm{kHz}$

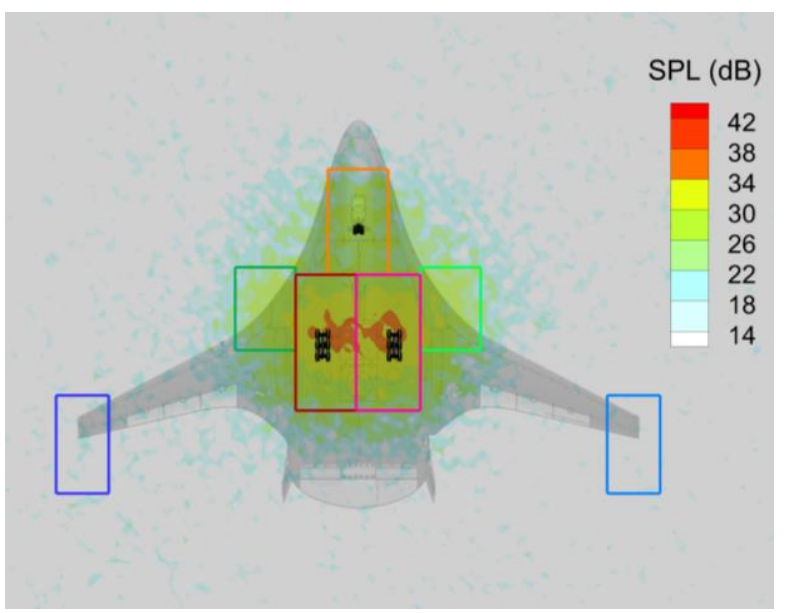

(d) $25 \mathrm{kHz}$

Figure 4. DAMAS noise source distribution maps; airframe configuration $A 1$; array at $X=16.4^{\prime}\left(\theta=87.6^{\circ}\right.$, $\left.\phi=0^{\circ}\right) ; \operatorname{Mach}=0.17$. 


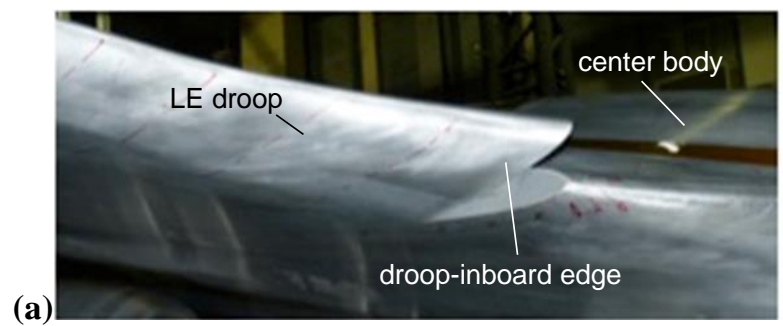

(a)

droop-inboard edge

Figure 5. LE droop; (a) inboard side-edge; (b) outboard side-edge.

Inspection of the noise maps generated for each one-third octave frequency band between $1.6 \mathrm{kHz}$ and $40 \mathrm{kHz}$ revealed that the wing tip/droop-outboard noise sources could be resolved between $2.5 \mathrm{kHz}$ and $8 \mathrm{kHz}$, while the landing gear and droop-inboard noise sources could be resolved fairly well between $2 \mathrm{kHz}$ and $20 \mathrm{kHz}$. Above 20 $\mathrm{kHz}$, the DAMAS maps display noise sources distributed over a broad region centered about the two main gear, and noise sources at the droop-inboard edges and at the nose landing gear can no longer be separated out. The broadening of the noise source distributions observed in the DAMAS maps (e.g., in Figs. 4c and 4d) with increase in frequency can be attributed to decorrelation effects ${ }^{14,15}$ from the test section shear layer. As the sound passes through the wind tunnel shear layer, it is scattered by turbulence, causing a decrease in the spatial coherence of the acoustic waves across the microphone phased array aperture. As explained in References 14 and 15, this loss in correlation between the signals received at the array microphones effectively decreases the sensitivity of the array, resulting in a loss in image resolution and estimated noise source levels, which are potentially too low or that decrease too rapidly with frequency (as the noise source distributions appear smeared and spread outside of pre-defined integration regions). The potential impact of decorrelation effects on the noise levels reported in the present analysis will be discussed in Section 4.2.

\section{Al component spectra}

The spectra of the noise radiating from different regions of the A1 model configuration are presented in Fig. 6. These regions are depicted in Fig. 4. They were devised to determine noise contributions from each landing gear, droop-inboard edge and wing tip/droop-outboard edge. It is seen from Fig. 6 that the noise radiating from the two main gear dominates the spectra over the full frequency range. The nose gear appears to be the next most significant noise contributor, followed by the droop-inboard edges and, lastly, the wing tips/ droop-outboard edges. Because of the model symmetry, closely matching spectral levels for matching components on the starboard- and port-sides of the model was expected. Differences in spectral level observed between matching components may be attributed to a combination of factors, including: (1) a potential skew of the test section flow (that could be induced by the asymmetric position of the walls surrounding the open test section), (2) a test section shear layer that may not be uniform across the model span (this could vary the amount of scattering experienced by the noise radiating from different parts of the model), and (3) a small yaw in the model support assembly.

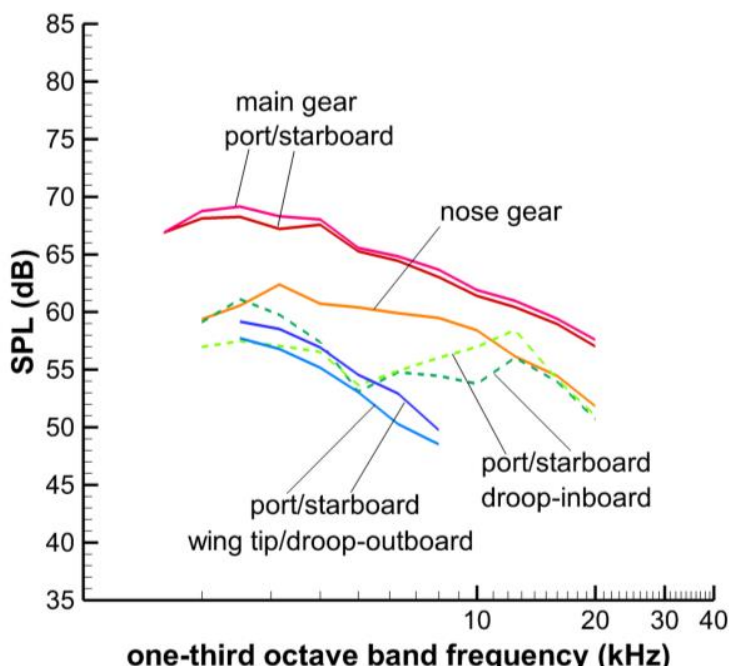

Figure 6. Noise component breakdown for airframe configuration A1. One-third octave band spectra. $M=0.17$; $\theta=87.6^{\circ}$ and $\phi=0^{\circ}$; distance to observer: $R=13$ '. 


\section{Al spectral directivity}

Directivity effects on the landing gear system, LE droop and wing tip noise spectra for flyover emission angles, $\theta$, of $59.2^{\circ}, 71.1^{\circ}, 87.6^{\circ}$ and $111.25^{\circ}$ are shown in Figure 7 . These data were acquired with a flow Mach number of 0.17 . In some cases, only a limited portion of the spectra is shown, as the corresponding noise sources could only be resolved over a limited frequency range. As in the previous figure, each spectrum is obtained through integration of the mean-squared pressures in the DAMAS maps generated for each array location. The integration regions are as defined in Fig. 4. Spectral levels are scaled to a common observer distance, R, of 13 feet. It is noted that for the data acquired at $\theta=111.25^{\circ}$, the noise source distribution in the DAMAS maps appeared somewhat smeared, as compared to the results obtained with the array positioned further upstream. This decrease in image resolution is likely associated with increased scattering due to the increased thickness of the shear layer at this most downstream location, as well as to differences between actual and assumed shear layer geometry that are more significant at this most downstream location. (In the data processing, the shear layer was modeled as an infinitesimally thin plane, parallel to the test section floor. Departure from this simplified model would affect the array delay and sum beamforming calculations.) Thus, spectral levels displayed for this polar angle may be especially affected by these effects.

For the nose gear directivity (Fig. 7a), spectral levels are observed to reduce as $\theta$ increases. The spectrum obtained at the most upstream location $\left(\theta=59.2^{\circ}\right)$ is 3 to $4 \mathrm{~dB}$ louder, above $2 \mathrm{kHz}$, than the spectrum obtained at the most downstream location $\left(\theta=111.25^{\circ}\right)$. At intermediate directivity angles, spectral levels are near the higher upstream levels below $7 \mathrm{kHz}$, and approach the lower downstream levels above $10 \mathrm{kHz}$. For the port main gear (Fig. 7b), the spectral levels appear less sensitive to directivity angle variation than for the nose gear. Spectra obtained at and upstream of $87.6^{\circ}$ are within $1.5 \mathrm{~dB}$ of each other, while the spectrum obtained at the largest polar angle is approximately $3 \mathrm{~dB}$ quieter. The same findings are observed for the starboard main gear (spectra not shown). For both the port and starboard droop-inboard edges, the spectra (shown for the starboard side in Fig. 7c) obtained above 5 $\mathrm{kHz}$, at (and upstream) of $87.6^{\circ}$, show little sensitivity to angle change and are within $1 \mathrm{~dB}$ of each other. Below 5 $\mathrm{kHz}$, spectral levels appear more sensitive to angle change and are seen to increase with polar angle. Noise levels measured at the most upstream location are 3 to $4 \mathrm{~dB}$ lower than those measured at the most downstream location. Finally, the spectral directivity of the noise radiating from the wing tip/droop-outboard region is shown in Fig. 7d. The noise from that region could only be resolved over a limited frequency range for the three largest polar angles $(\theta$ $=71.1^{\circ}, 87.6^{\circ}$ and $111.25^{\circ}$ ). The corresponding spectra are within $2 \mathrm{~dB}$ of each other with lowest levels measured downstream, at $\theta=111.25^{\circ}$.

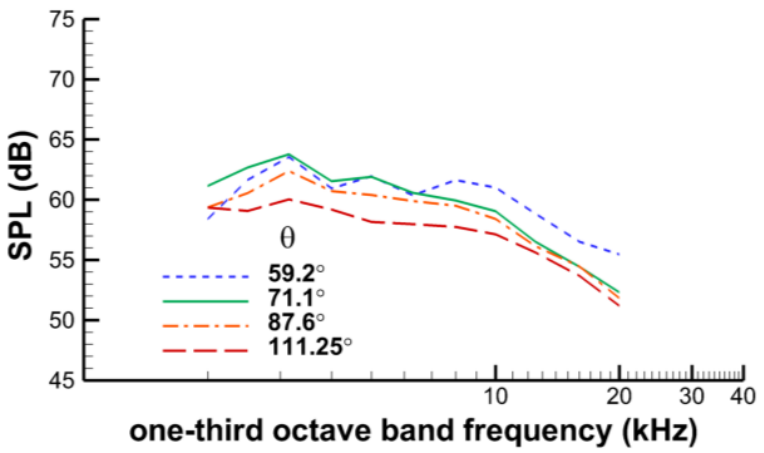

(a)

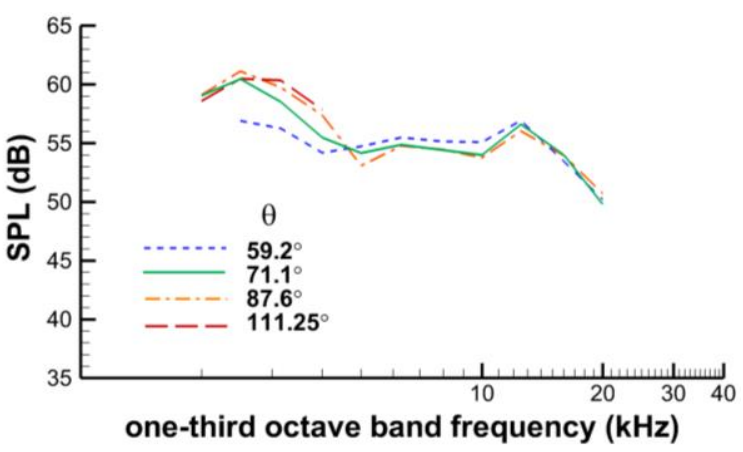

(b)
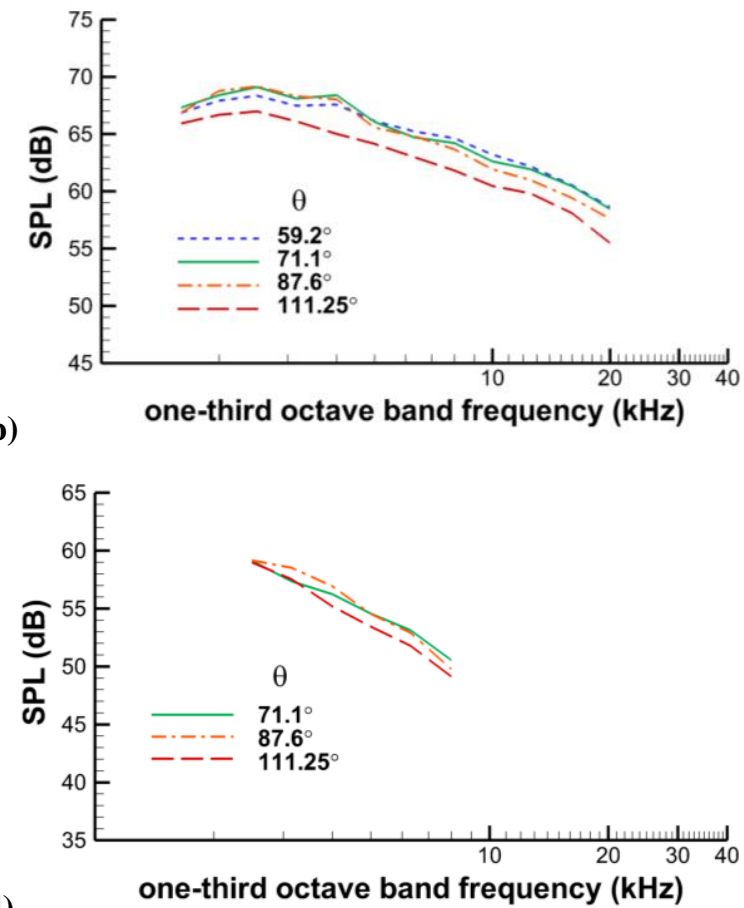

(d) one-third octave band frequency $(\mathrm{kHz})$

Figure 7. Component noise flyover directivity for A1 airframe configuration. One-third octave band spectra.

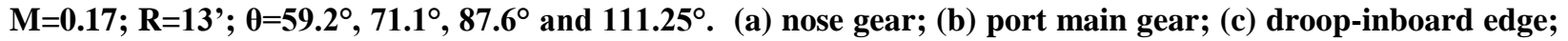
(d) wing tip/droop-outboard region. 


\section{Al Mach number scaling}

The component noise spectra obtained for the A1 configuration, at its design flow Mach number of 0.19 , are displayed in Fig. 8, together with the spectra obtained at a flow Mach number of 0.17. These data were acquired from the same microphone phased array location $\left(X=16.4\right.$ feet). The polar emission angle, $\theta$, is $87.6^{\circ}$ for $M=0.17$ and $87^{\circ}$ for $\mathrm{M}=0.19$. In Fig. 8 b, the spectral levels are scaled with the $\mathrm{n}^{\text {th }}$ power of Mach number and the frequency normalized in a manner consistent with Strouhal scaling. The noise from the droop-inboard region is found to approximately scale with $\mathrm{M}^{5.5}$, while the noise from the wing tip/droop-outboard region is found to best scale with $\mathrm{M}^{5}$. It is noted that although wing tip noise has been reported ${ }^{16}$ to scale with a power of Mach number that is between 5 and 6 , the noise radiating from the wing tip/droop-outboard region includes the noise radiating from both the wing tip and the droopoutboard edge. The wake from the latter may also affect the noise generation at the wing tip. For landing gear noise, although a $6^{\text {th }}$ power of Mach number scaling ${ }^{17,18}$ collapses the main gear spectra and nose gear spectra to within 0.5 $\mathrm{dB}$ and $1 \mathrm{~dB}$, respectively, the collapse is slightly improved with $\mathrm{M}^{5.5}$ scaling.

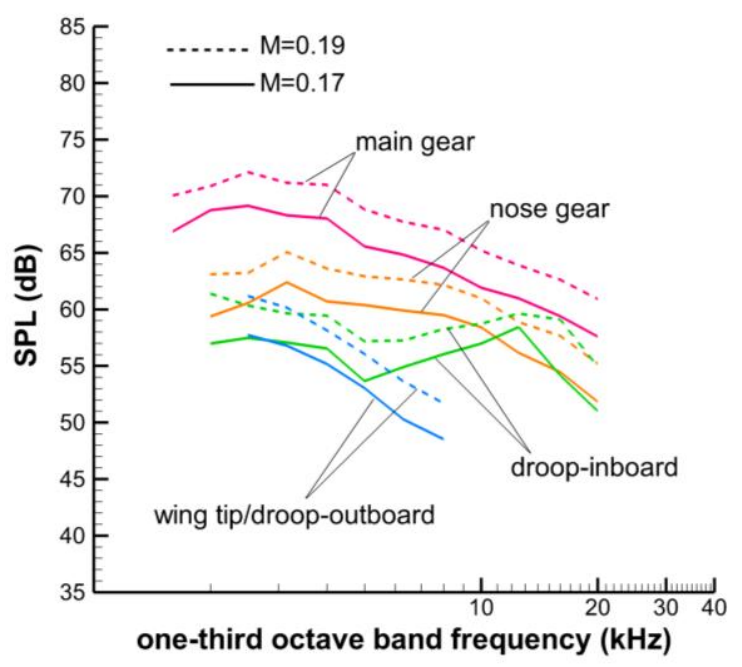

(a)

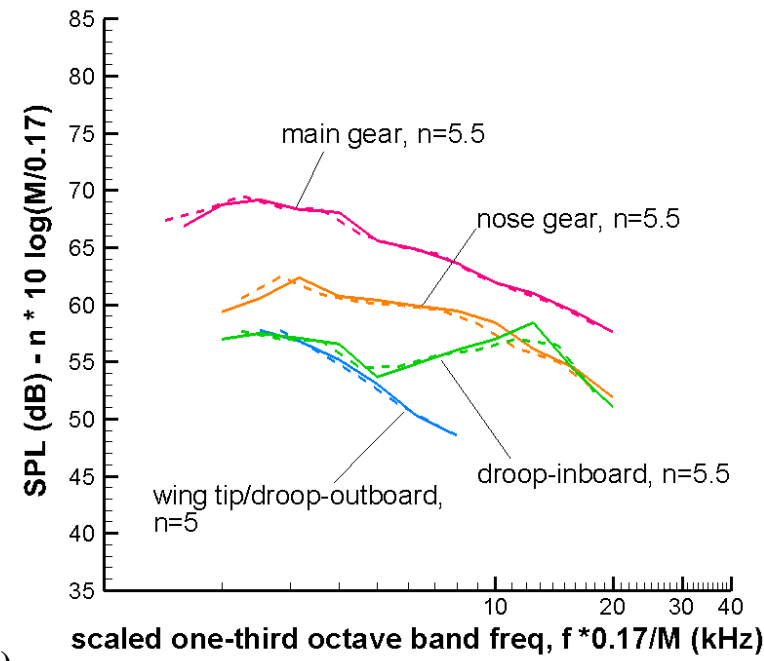

Figure 8. Mach number scaling. A1 airframe configuration, port side components. One-third octave band spectra. Array streamwise station: $X=16.4$ '. Distance to observer: $R=13$ '. (a) without scaling; (b) with Mach number scaling and frequency normalized.

\section{A2 noise source distribution maps}

Noise source distribution maps for the A2 configuration are displayed in Fig. 9. The model is set at $15.5^{\circ} \mathrm{AOA}$, the flow Mach number is 0.17 , and the array streamwise station is $X=16.4$ feet. The corresponding polar emission angle, $\theta$, is $90.6^{\circ}$. Although elevons E1 through E4 are deflected (at $\left.-10^{\circ}\right)$, the DAMAS maps do not reveal any noise sources in the vicinity of the deflected elevons. Even though strong noise sources have been shown to develop at the side-edges of deployed elevons (or flaps ${ }^{19,20}$ ), the deflection angle of the elevons in the present configuration is small and may lead to noise sources that are too weak to be resolved in the presence of other, much stronger, noise sources. (The measurement of elevon side-edge noise is revisited at the end of Section 4.1.)

As with configuration A1, the DAMAS maps for configuration A2 reveal noise sources at the nose and main landing gear locations, at the droop-inboard edges and in the wing tip/droop-outboard regions. However, the noise sources in the droop-inboard and wing tip/droop-outboard regions appear stronger than in the noise maps generated for configuration A1 (Fig. 4). 


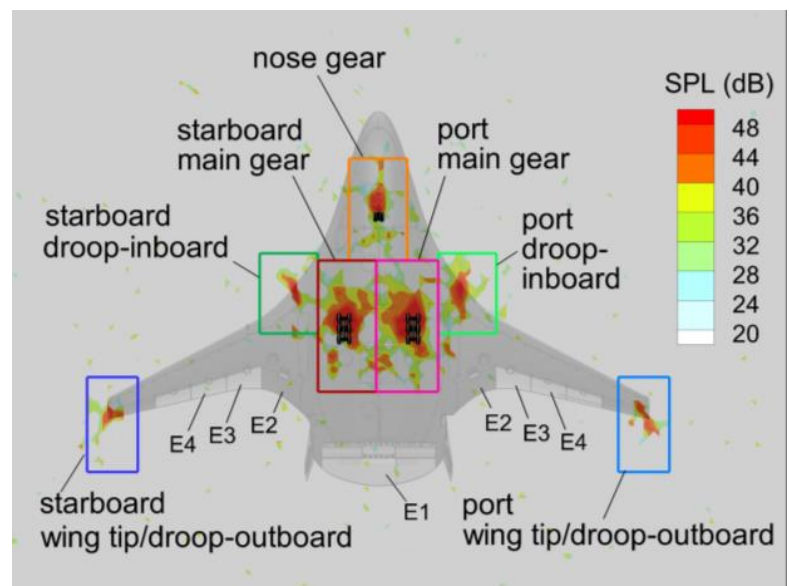

(a) $3.15 \mathrm{kHz}$

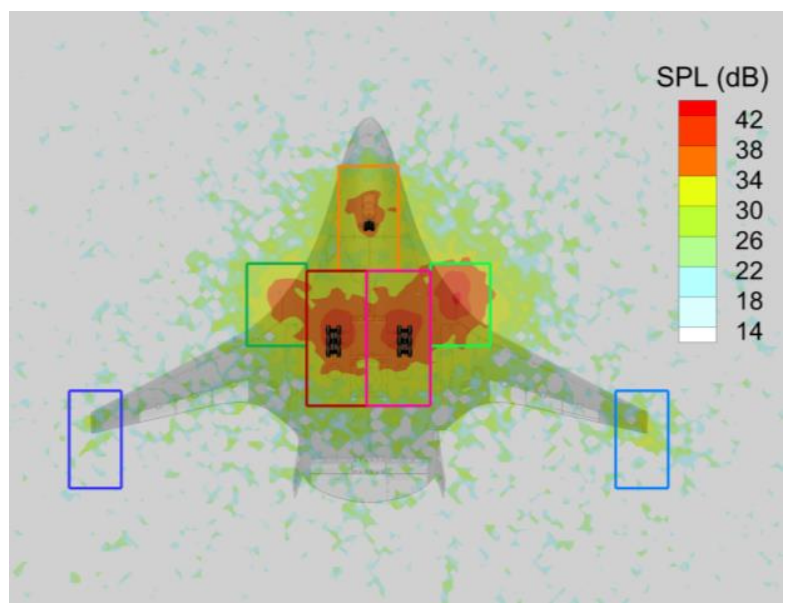

(c) $12.5 \mathrm{kHz}$

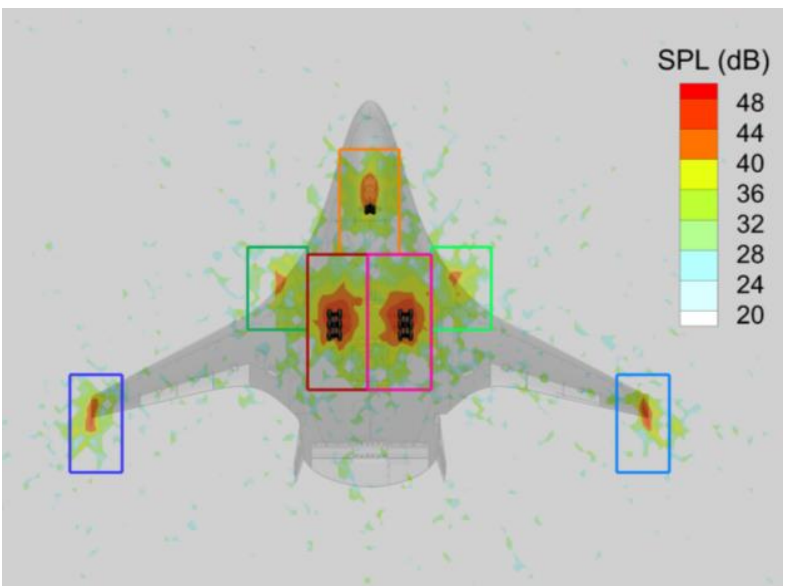

(b) $6.3 \mathrm{kHz}$

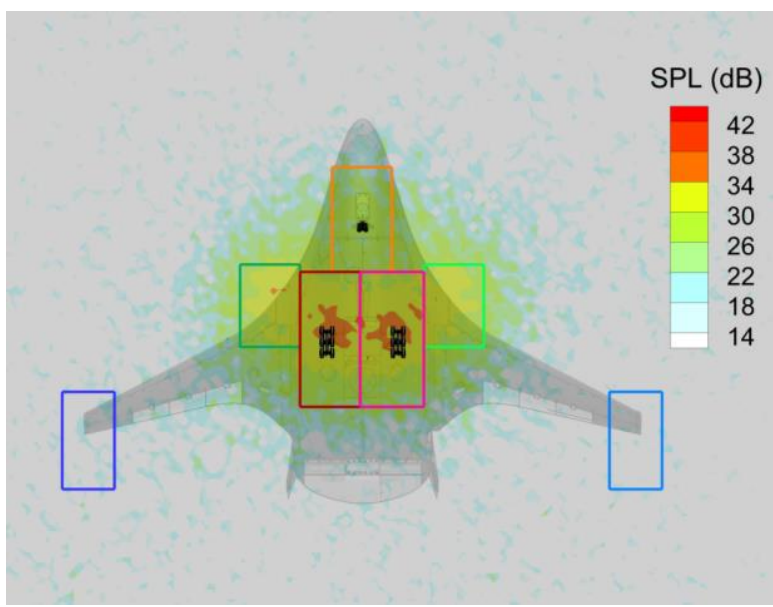

(d) $25 \mathrm{kHz}$

Figure 9. DAMAS noise source distribution maps. Airframe configuration A2. Array streamwise station: $X=16.4^{\prime}\left(\theta=90.6^{\circ}, \phi=0^{\circ}\right)$; Mach $=0.17$.

\section{A2 component spectra}

The noise component spectra obtained for A1 and A2 are compared in Fig. 10. Spectra are shown for the frequency range over which the noise sources could be resolved. The angle of attack change from $13.1^{\circ}$ to $15.5^{\circ}$ is seen to lead to a significant increase in the noise radiating from the droop-inboard and wing tip/droop-outboard regions. Thus, A2 spectral levels for the port and starboard droop-inboard noise are, respectively, up to 5 and $4 \mathrm{~dB}$ higher than for A1. For the A2 configuration, droop-inboard noise levels exceed nose landing gear levels above 10 $\mathrm{kHz}$ and are only $1 \mathrm{~dB}$ lower than main landing gear levels between $12.5 \mathrm{kHz}$ and $16 \mathrm{kHz}$. Similarly, A2 spectral levels for the port and starboard wing tip/droop-outboard noise are, respectively, up to 7 and $4 \mathrm{~dB}$ higher than for A1 and are only 1 to $3 \mathrm{~dB}$ lower than nose gear levels between $3.15 \mathrm{kHz}$ and $8 \mathrm{kHz}$. In contrast, noise from the nose and main landing gear system is slightly reduced (by less than $1 \mathrm{~dB}$ ) with the AOA change from $13.1^{\circ}$ to $15.5^{\circ}$. Although the change in angle of attack is associated with a slight change in observer directivity (from $\theta=87.6^{\circ}$ to $\theta=90.6^{\circ}$ ), this small decrease in noise is likely due to lower local flow velocities on the model pressure side because of the AOA increase. Finally, because noise from the main landing gear system dominates (for both A1 and A2), the effect of the airframe configuration change on the overall noise radiating from all seven component regions combined is very small. As seen in Fig. 10d, the configuration change from A1 to A2 leads to a small decrease in noise below $5 \mathrm{kHz}$ and to a small increase in noise above $12.5 \mathrm{kHz}$; both are less than $1 \mathrm{~dB}$. Note, however, that when tested at their respective design speeds of $\mathrm{M}=0.19$ (A1) and 0.21 (A2), overall component noise for the $\mathrm{A} 2$ configuration (result not shown) is approximately $2 \mathrm{~dB}$ louder than for $\mathrm{A} 1$, across the measured frequency range. 

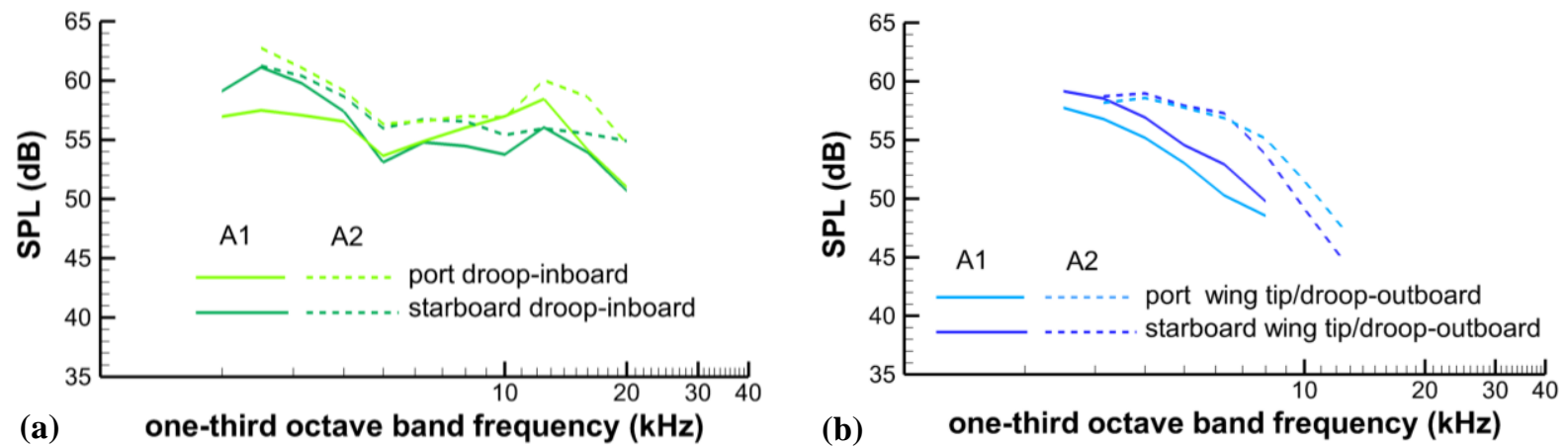

(a)

one-third octave band frequency $(\mathrm{kHz})$

(b)

one-third octave band frequency $(\mathrm{kHz})$
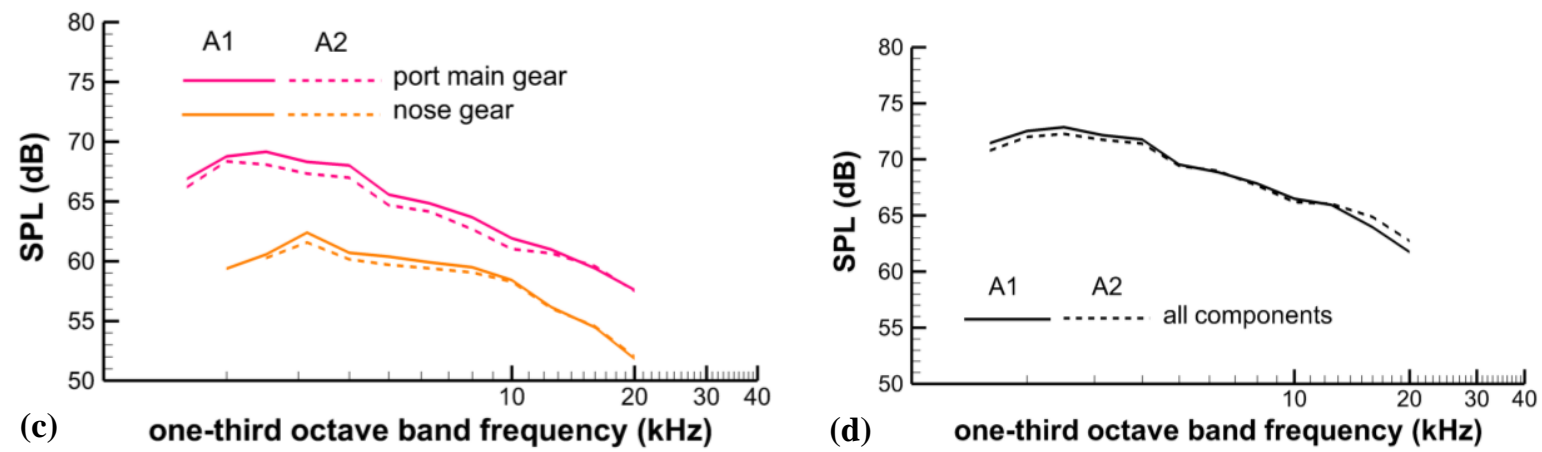

Figure 10. Noise component breakdown. A2 versus A1 airframe configurations. One-third octave band spectra. $M=0.17$; array streamwise station $X=16.4^{\prime} ; \mathrm{R}=13$ '; (a) droop-inboard noise; (b) wing tip/droop-outboard noise; (c) nose and main landing gears; (d) total noise from all component regions.

\section{A2 Mach number scaling}

The component noise spectra obtained for the A2 configuration, at its design speed of $\mathrm{M}=0.21$, are displayed in Fig. 11, together with the spectra obtained at $M=0.17$. As with the A1 configuration (Fig. 8), data shown were acquired with the microphone phased array positioned at $\mathrm{X}=16.4$ feet. The spectral levels are scaled with the $\mathrm{n}^{\text {th }}$ power of Mach number and the frequency normalized. The nose and main gear spectra are scaled with $\mathrm{M}^{5.5}$, providing a good collapse of the spectra only between $2 \mathrm{kHz}$ and $6.3 \mathrm{kHz}$. At higher frequencies, the nose and main gear spectra are found to scale better with smaller powers of Mach number, hence further departing from the expected $\mathbf{M}^{6}$ scaling for landing gear noise. This change in velocity dependence to a smaller power of Mach number in the higher frequency range may be associated with increased decorrelation effects from the increased flow speed (hence, increased turbulence intensity $)^{21}$. However, the variability found in scaling behavior of complex landing gear geometries has been reported $^{22,23}$ and is discussed in Reference 24.

The droop-inboard noise spectra are found to only approximately scale with $\mathrm{M}^{5}$, while the wing tip/droopoutboard noise spectra are found to best scale with $\mathrm{M}^{4}$ (as compare to $\mathrm{M}^{5}$ for the A1 configuration). The latter "drift" in velocity dependence to a smaller power of Mach number may also be related to increased decorrelation effects, but it may also be associated with a modified interaction (induced by the small change in AOA) between the droopoutboard edge wake and the wing tip flow. 


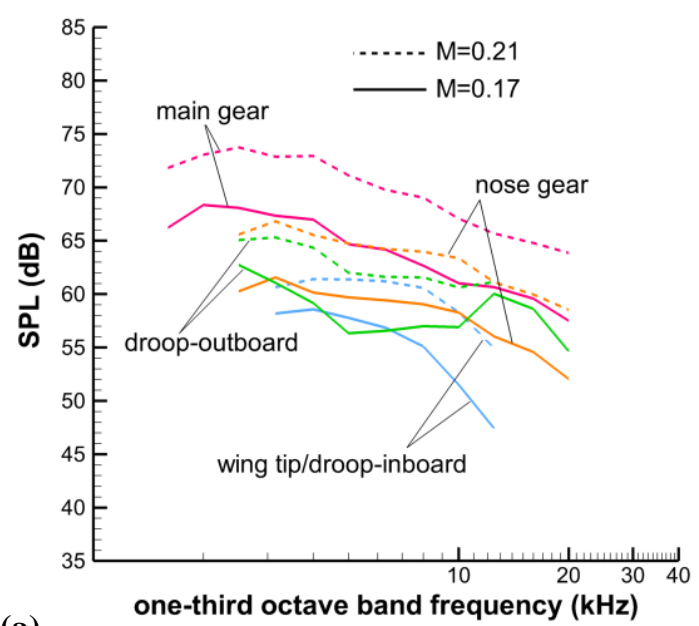

(a)

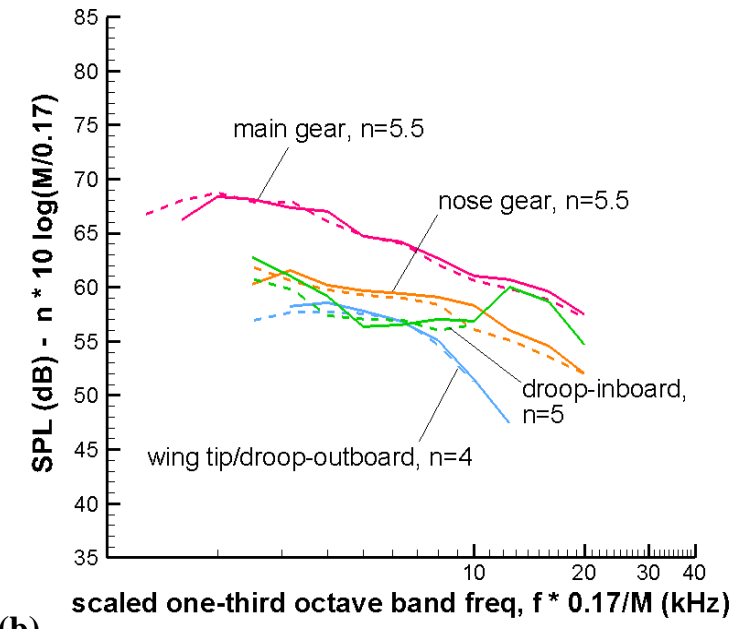

(b)

Figure 11. Mach number scaling. A2 airframe configuration, port side components. One-third octave band spectra. $\mathrm{R}=13$ '; array streamwise station $\mathrm{X}=16.4$ '. (a) without scaling; (b) with Mach number scaling and normalized frequency.

\section{Elevon noise study}

Additional noise measurements were performed with the LE and landing gear system stowed to better isolate noise from the elevon region of the N2A-EXTE model. These data were acquired for two model configurations that were not intended to match specific flight conditions. In the first configuration, elevons E1 through E4 were deflected at $-10^{\circ}$. In the second configuration, only elevons E1, E3 and E5 were deflected at $-10^{\circ}$. With the first configuration, data were acquired with the model set at $0^{\circ} \mathrm{AOA}$ and for three flow Mach numbers $(0.17,0.19$ and 0.21$)$. With the second configuration, data were acquired for two AOA, $0^{\circ}$ and $13.1^{\circ}$, and a flow Mach number of 0.17 . As with the approach flight configurations, the background CSM used in the processing of the microphone phased array data was obtained from measurements performed with the landing gear components and wing leading edge stowed, elevons undeflected, the verticals removed and the airframe at $0^{\circ} \mathrm{AOA}$. The results shown were obtained with the microphone phased array positioned at $X=16.4$ feet. Note that the $13.1^{\circ}$ AOA case also allows for a measure of wing tip noise without the LE droop deployed, i.e., without possible interaction from the LE droop outboard side edge.

\section{E1-E4 at $-10^{\circ}, A O A=0^{\circ}$ :}

A sample noise source distribution map obtained for this first configuration is displayed in Fig. 12. The map shown is for the $6.3 \mathrm{kHz}$ one-third octave band, and the freestream flow Mach number is 0.17 . Although elevons E1 through E4 are deflected (at $-10^{\circ}$ ), the DAMAS maps only reveal noise sources at the outboard side edge of elevon E4, as well as at the small gap that opens up between E3 and E4 when these elevons are deflected. This was also observed in the DAMAS maps generated over the rest of the frequency range. The sound pressure levels associated with these noise sources are also significantly lower than those observed for the other noise components resolved in the approach flight configuration cases. Noise sources at the sides edges of E1 and E2 may be too close to background noise levels to be resolved.

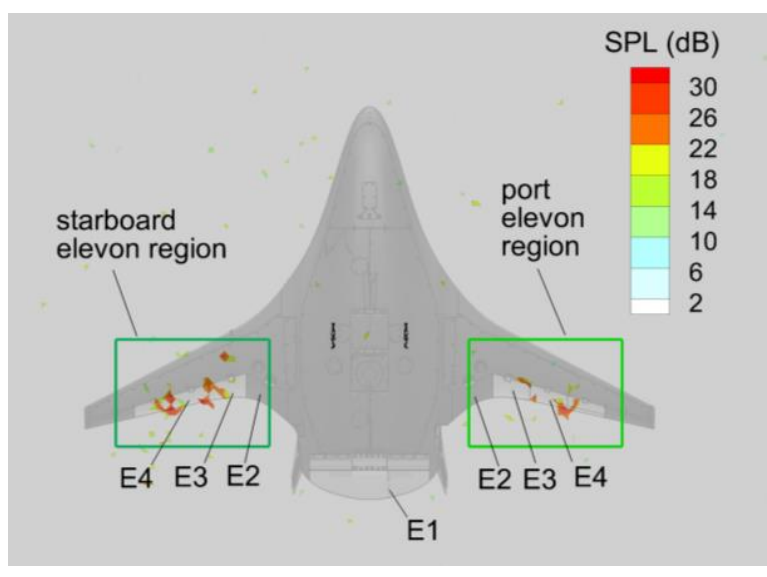

Figure 12. DAMAS noise source distribution maps. E1-E4 at $-10^{\circ}, \mathrm{AOA}=0^{\circ}, \mathrm{M}=0.17, \mathrm{f}_{1 / 3}=6.3 \mathrm{kHz}$.

The spectra of the noise radiating from the starboard elevon region (defined in Fig. 12) are displayed in Fig. 13 for the different flow Mach numbers tested. In Fig. 13b, the spectral levels are scaled with the $6^{\text {th }}$ power of Mach number and the frequency normalized. This scaling is seen to collapse the spectra within $1.5 \mathrm{~dB}$ below $10 \mathrm{kHz}$ and within $3 \mathrm{~dB}$ above $10 \mathrm{kHz}$. 
(a)

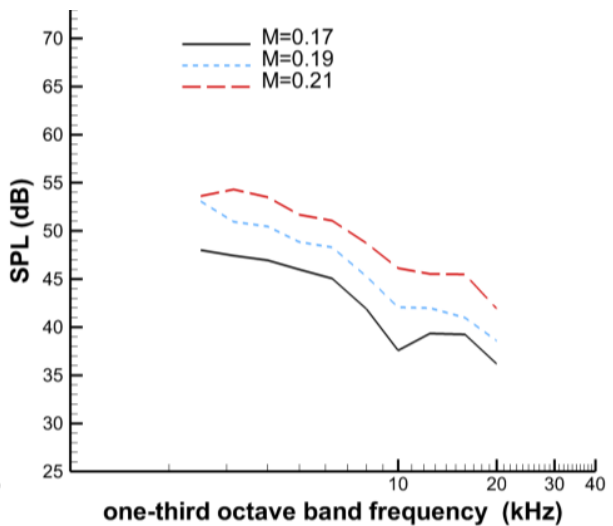

(b)

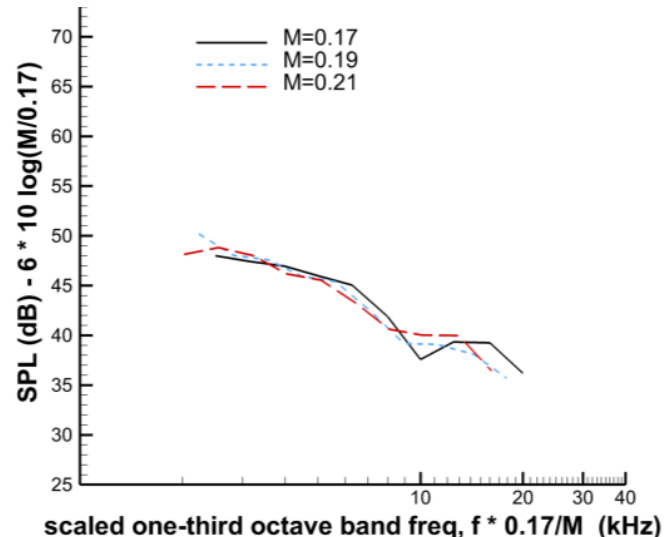

Figure 13. Integrated one-third octave band spectra of elevon noise (starboard side) for $M=0.17,0.19$ and 0.21 ; (a) without scaling; (b) with $\mathbf{M}^{6}$ scaling and frequency normalized.

\section{E1, E3 and E5 at -10deg, $A O A=0^{\circ}$ and $13.1^{\circ}$ :}

Noise source distribution maps obtained with elevons E1, E3 and E5 deflected and for the two AOA tested are presented in Fig. 14 (for the $6.3 \mathrm{kHz}$ one-third octave band). The freestream flow Mach number is 0.17. The noise source distribution maps show noise sources at the inboard and outboard side-edges of E3 and E5. As the AOA is changed from $0^{\circ}$ to $13.1^{\circ}$, these noise sources appear to strengthen, and noise sources at the model wing tips are revealed.

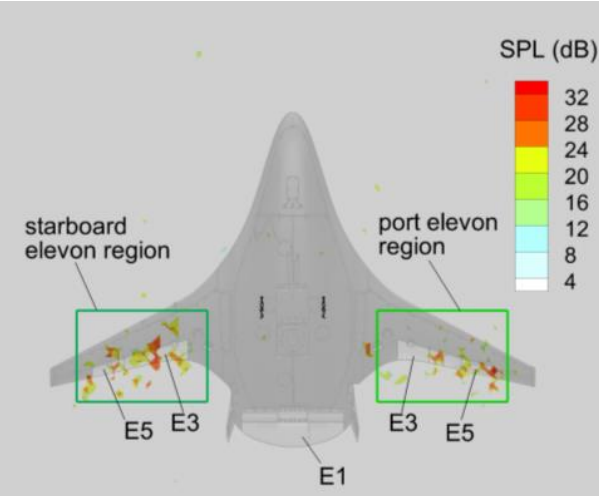

(a)

(b)

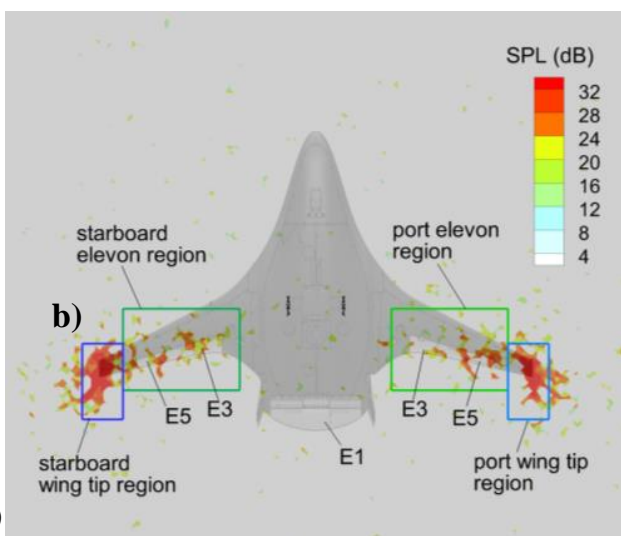

Figure 14. DAMAS noise source distribution maps; E1, E3 and E5 at $-10^{\circ}$; array streamwise station $X=16.4^{\prime}$; Mach $=0.17 ; \mathrm{f}_{1 / 3}=6.3 \mathrm{kHz} ;\left(\right.$ a) $\mathrm{AOA}=0^{\circ} ;$ (b) $\mathrm{AOA}=13.1^{\circ}$.

The spectra of the noise radiating from the starboard elevon and wing tip regions are displayed in Fig. 15. As indicated by the DAMAS maps, the elevon noise is seen to increase with AOA (by up to $2 \mathrm{~dB}$ ). For the $13.1^{\circ}$ AOA case, below $12.5 \mathrm{kHz}$, the noise from the wing tip region is up to $7 \mathrm{~dB}$ louder than elevon noise. Note that unlike in the A1 and A2 test cases, the noise from the wing tip region is not affected by the outboard side-edge of the LE droop. Also, because the $0^{\circ} \mathrm{AOA}$ case is used for background noise subtraction, noise from the wing tip region represents the change in wing tip noise associated with the change in AOA. (Nevertheless, this measure is a very good representation of wing tip noise, as noise measured from the wing tip region at $0^{\circ} \mathrm{AOA}$ was found to be at least $7 \mathrm{~dB}$ lower across the frequency range of interest than that measured at $\left.13.1^{\circ} \mathrm{AOA}\right)$.

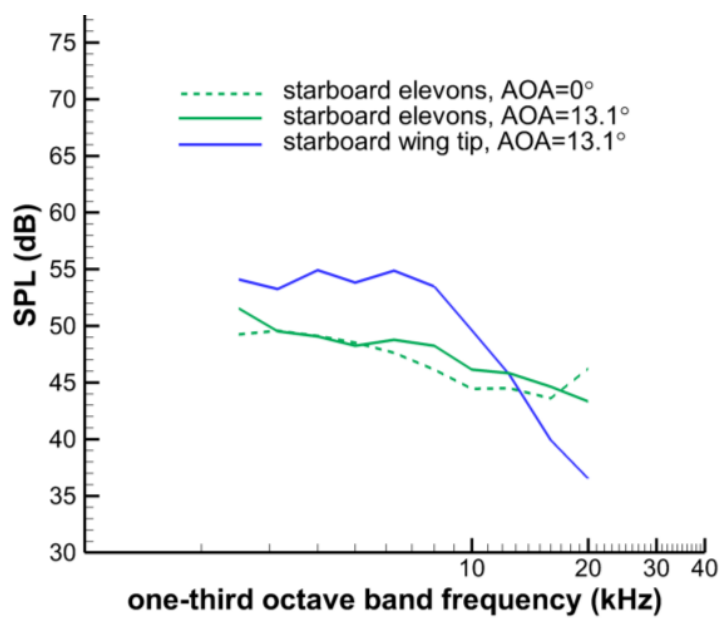

Figure 15. Integrated spectra. E1, E3 and E5 at $-10^{\circ} ; \mathrm{X}=16.4^{\prime} ; \mathrm{R}=13$ '; $\mathrm{M}=0.17$. 


\subsection{Overhead and sideline microphone measurements}

The data acquired from the overhead and sideline microphones at different streamwise stations in the test section were used to obtain additional directivity information from the N2A-EXTE landing gear components. Measurements performed with and without the landing gear system deployed were acquired for the A1 airframe configuration and a flow Mach number of 0.17. (The overhead and sideline microphones were also used to obtain additional directivity information for the $\mathrm{A} 1$ and $\mathrm{A} 2$ configurations at different speeds. These measurements were taken with and without the model installed in the test section. Some of these results are included in Reference 4.)

\section{Port-side main landing gear noise directivity}

Measurement locations for the overhead and sideline microphones are shown in Fig. 16a. The noise spectra obtained from a center overhead microphone location are shown in Figure 16b when all landing gear components are stowed and when only the port-side main landing gear is deployed. The noise spectrum for the empty test section is also shown. It is seen from Fig. 16b that the noise measured from the N2A-EXTE airframe is well above the wind tunnel background noise over the whole frequency range, and that above $4 \mathrm{kHz}$, the noise from the airframe with the port-side landing gear deployed is 2 to $3 \mathrm{~dB}$ higher than when all landing gear components are stowed. Subtracting the acoustic pressure field measured from the overhead and sideline microphones when all gear components are stowed from that measured when the port-side gear is deployed provides a measure of the pressure field generated by the port-side gear alone. The noise (shown in terms of polar and azimuthal angles, $\theta$ and $\phi$ ) is presented in Fig. 17 for a sample of one-third octave band frequencies. In that figure, the pressure field is projected onto a hemisphere of 13foot radius centered at the origin of the coordinate system used in this analysis to define observer locations in terms of polar and azimuthal emission angles. (The origin of the coordinate system was defined in Section 3, as a point located mid-way between the two installed main gear and level with the mid-length of the main struts.) As illustrated in Fig. 16a, $\theta$ is measured relative to the longitudinal axis of the N2A-EXTE model, and positive $\phi$ values are on the starboard side of the airframe.

(a)

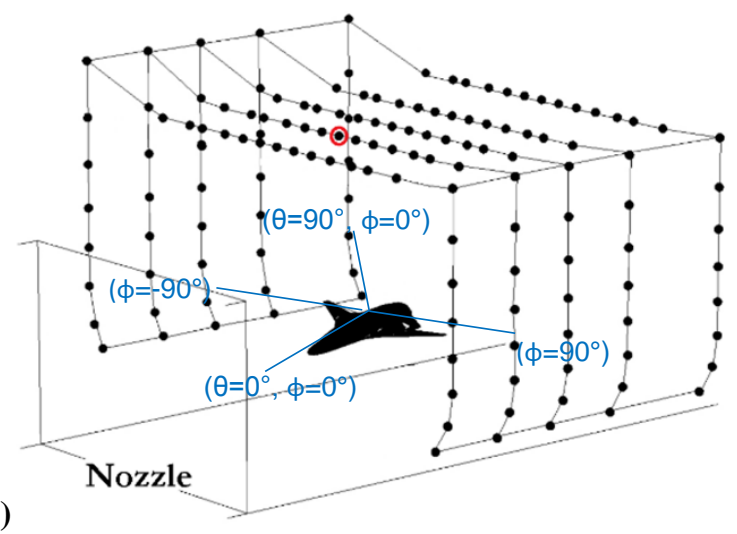

(b)

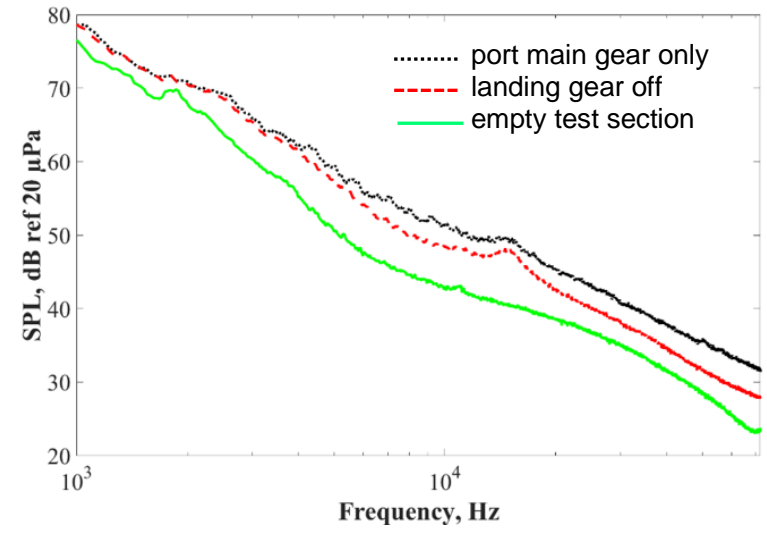

Figure 16. (a) Overhead and sideline microphone measurement locations; (b) Auto-spectra obtained from the center overhead microphone (circled in red in (a)) for the empty test section and two airframe configurations. $\mathrm{AOA}=13.1^{\circ} ; \mathrm{M}=\mathbf{0 . 1 9}$.

Fig. 17 shows sound pressure level contours for one-third octave frequency bands spanning $5 \mathrm{kHz}$ to $40 \mathrm{kHz}$. The same color level scale is used for each contour plot. Note that the portion of the contour (between, approximately, $\phi=$ $-50^{\circ}$ and $-70^{\circ}$ ) that is left out in each plot corresponds to a region surveyed by a questionable microphone. Higher noise levels are found on the starboard side of the model, which (referring to Fig. 3b) represents the non-door side of the gear where the noise radiating from the main strut, side braces, and wheel well is not partially shielded by the door that is attached to the port side of the landing gear main strut. Thus, for $\theta \leq 110^{\circ}$ and $0^{\circ} \leq|\phi| \leq 50^{\circ}$, noise levels on the starboard side are approximately 2 to $3 \mathrm{~dB}$ higher than on the port side. However, for $\theta \geq 120^{\circ}$ and $0^{\circ} \leq|\phi| \leq 50^{\circ}$, noise levels on the starboard side appear consistently lower than on the port side. For higher azimuthal angles $\left(|\phi|>50^{\circ}\right)$ and the range of polar angles surveyed, noise levels on the starboard and port sides are similar. 

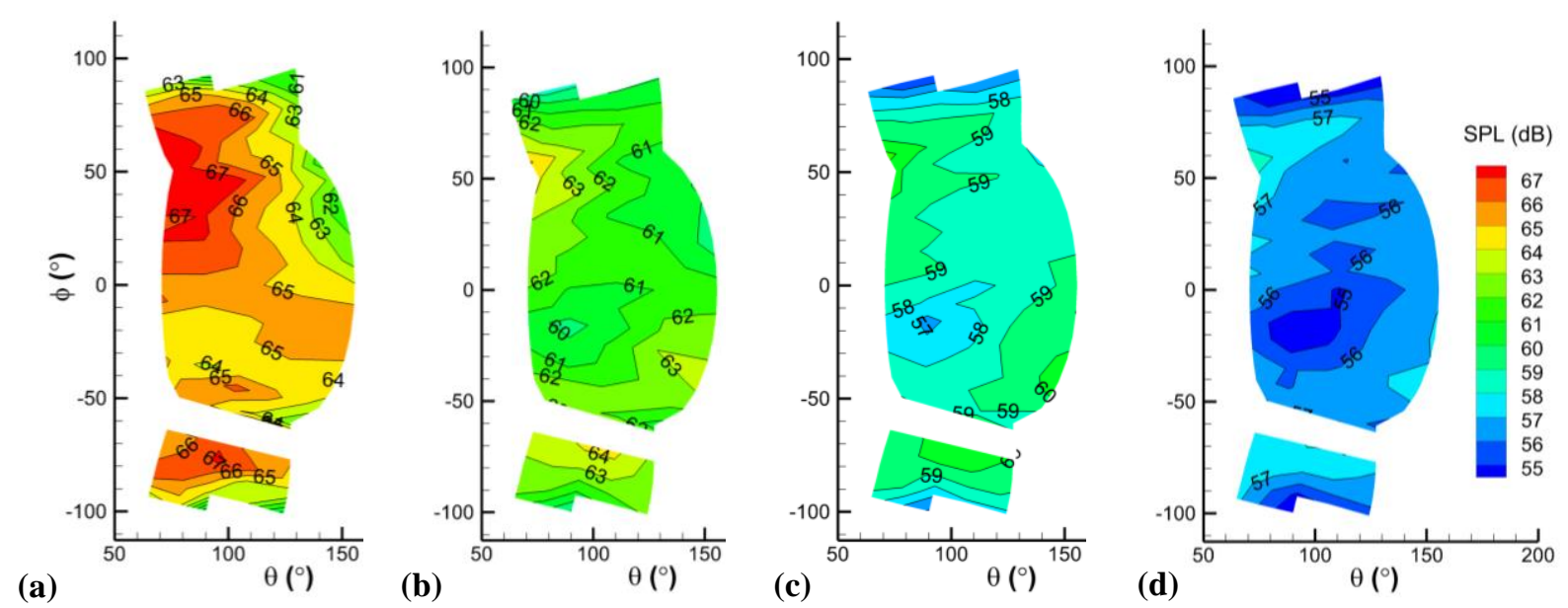

Figure 17. Noise directivity contours for the port-side (only) main landing gear for observers located on a 13foot radius hemisphere; the flow Mach number is 0.17 ; one-third octave band frequency: (a) $5 \mathrm{kHz}$; (b) $16 \mathrm{kHz}$; (c) $25 \mathrm{kHz}$; (d) $40 \mathrm{kHz}$.

Noise directivity of complete landing gear system

Similarly, subtracting the acoustic pressure field measured from the overhead and sideline microphones when all landing gear components are stowed from that measured when the full landing gear system is deployed provides a measure of the pressure field generated by the landing gear system alone. The resulting pressure field is presented in Fig. 18 for the same one-third octave band frequencies.

Highest noise levels are found at lower polar angles (i.e., overhead and forward of the N2A-EXTE). Around the flyover line, for $-30^{\circ} \leq|\phi| \leq 30^{\circ}$, there is an approximate $2 \mathrm{~dB}$ change in sound pressure level between the most upstream and downstream polar angles. That number increases to approximately $3 \mathrm{~dB}$ at larger sideline angles $\left(30^{\circ} \leq|\phi|\right)$. Noise levels also appear to be generally higher azimuthally near the sideline at $30^{\circ} \leq|\phi| \leq 65^{\circ}$ (for the lower polar angles).
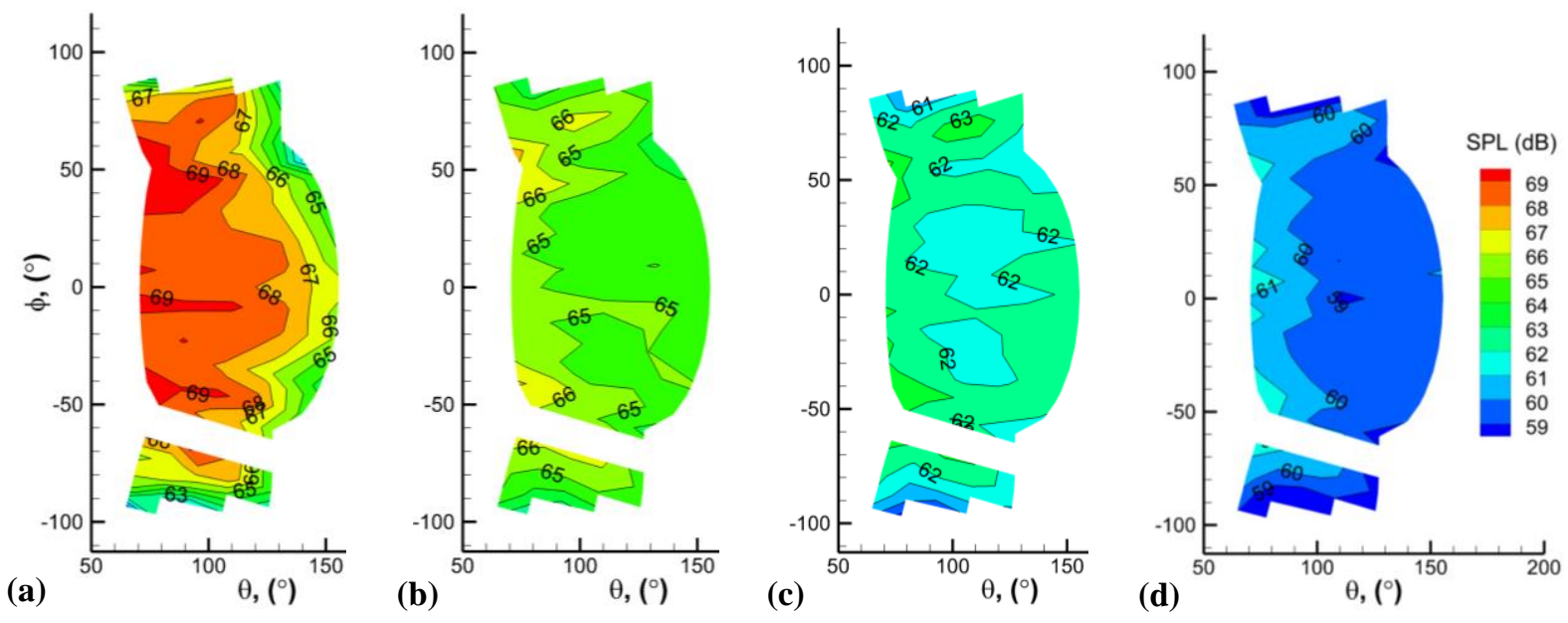

Figure 18. Key same as for Figure 17, except this is for the complete landing gear system.

Single microphone and array measurements comparison:

To illustrate microphone phased array decorrelation effects on measured spectral levels, DAMAS integrated spectra for the isolated port main gear test case discussed in this section are compared to that obtained from the centerline microphone of the overhead traverse. It is noted that autospectral levels measured from a single microphone should not be reduced due to scattering because the microphone "sees" the direct radiated noise field summed with the scattered noise field. Thus, comparing spectral levels from a single microphone with that obtained from the microphone phased array can provide a measure of $\mathrm{dB}$ loss due to decorrelation effects for a given noise source integration region.

The DAMAS spectra displayed in Fig. 19a are obtained from integration of noise source distributions over two regions: (1) a small region that is of the same size as that used in Section 4.1 to determine spectral levels for the port main gear in configurations A1 and A2, and (2) a large region that still captures most of the (broadened) noise source 
distributions at higher frequencies. A sample noise source distribution map obtained for this test case is shown in Fig. $19 \mathrm{~b}$, together with the small and large integration regions discussed above. In this analysis, the array is positioned at emission angles, $\theta=87.6^{\circ}$ and $\phi=0^{\circ}$. Corresponding single microphone spectral levels are extracted from the contour plots generated from the overhead and sideline microphone measurements for each one-third octave band frequency. As seen in Fig. 19a, below $4 \mathrm{kHz}$, spectral levels from the two DAMAS integration regions are nearly in agreement as the prominent noise source distributions included in the large region are also included in the small region. In contrast, spectral levels from the single microphone are sometimes too low due to background noise levels being nearly equal to the noise levels from the primary field in that low frequency range (see Fig. 16b). Between 4 and 8 $\mathrm{kHz}$, the DAMAS integrated spectrum from the small region is within $0.5 \mathrm{~dB}$ of the single microphone levels. Between 10 and $40 \mathrm{kHz}$, this difference in spectral levels progressively grows from, approximately, $1 \mathrm{~dB}$ at $10 \mathrm{kHz}, 1.8 \mathrm{~dB}$ at $20 \mathrm{kHz}, 2.5 \mathrm{~dB}$ at $30 \mathrm{kHz}$ and $3 \mathrm{~dB}$ at $40 \mathrm{kHz}$. However, integrating over the larger region is seen in Fig. 19a to significantly recover the total noise spectral output from the port main gear.

This comparison substantiates that spectral levels obtained from the microphone phased array are affected by decorrelation effects (especially as frequency increases). However, it only provides a quantification of these effects for this particular test case. The decorrelation effects on the integrated spectral levels of the different noise sources examined in this paper are affected by the array streamwise station, the flow speed, the size of the integration region and the presence and proximity of other noise sources.

As was shown in Section 4.1 for elevon and wing tip noise, the measurement of weaker noise sources can be significantly improved by removing (when possible) other more dominant noise sources and by subtracting corresponding background data to best "isolate" the source of interest from other noise sources. This approach was also used to obtain additional phased array measurements of the LE droop side-edge and port main gear noise sources (results not shown). Scattering effects can also be circumvented with single microphone measurements (as shown in this section for the port main gear and the complete landing gear system) when the noise source of interest is "loud enough".
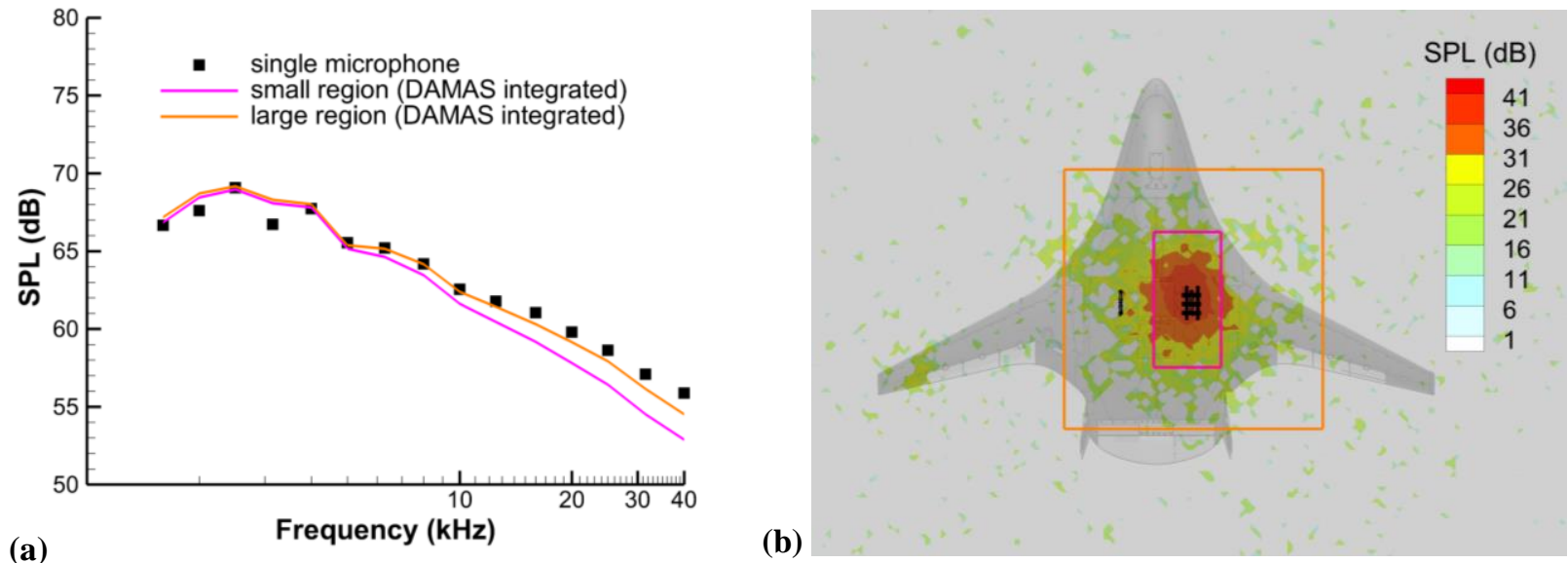

Figure 19. Only port main gear deployed; $M=0.17 ; \theta=87.6^{\circ} ; \phi=0^{\circ}$. (a) one-third octave band spectra; (b) DAMAS map, $\mathbf{f}_{1 / 3}=12.5 \mathrm{kHz}$.

\section{Summary}

Airframe noise measurements from an HWB aircraft configuration called N2A-EXTE are reported in this paper. This study is part of a high fidelity aeroacoustic test that was conducted at NASA Langley in the 14- by 22-Foot Subsonic Tunnel facility. The HWB model is a high fidelity, full span, 5.8\% scale model built with a modular design to allow testing of different airframe configurations. The airframe components include a drooped and a stowed leading edge to model high lift and "clean" wing configurations, elevons that can be deflected along the wing trailing edge to match specific flight conditions, twin verticals, and nose and main landing gear with geometrically scaled wheelwells. The model is mounted inverted in the test section, and noise measurements are acquired from an overheadtraversing microphone phased array as well as from overhead- and sideline-traversing microphones, all positioned outside of the test section flow.

Noise source distribution maps and component noise spectra obtained from microphone phased array measurements along the aircraft flyover line are presented for airframe configurations (A1 and A2) that correspond to two approach flight conditions. For both A1 and A2, the model is configured with LE droop and with the landing gear system deployed. Noise source distribution maps reveal noise sources at the nose and main landing gear locations, at 
the LE droop inboard side-edges, and at the wing tips / LE droop outboard side-edges. Ranking of the integrated onethird octave band spectra obtained from the noise source distribution maps for each noise component shows the port and starboard main landing gear to be the dominant contributor to the total airframe noise, followed by the nose gear, the inboard side-edges of the LE droop, and the wing tip/LE droop outboard side-edges. Additional measurements performed with the landing gear system stowed reveal noise sources at some of the deployed elevon side-edges. Spectral levels associated with these noise sources are also significantly lower than those observed for the other noise components.

Examination of the velocity dependence of the component noise levels show that the nose gear, main gear and LE droop inboard side-edge spectra best follow a $\mathrm{M}^{5.5}$ scaling for the two lower flow speeds tested, while noise from the wing tip/LE droop outboard side-edge best scales with $\mathbf{M}^{5}$. Scaling between the lowest and highest speeds tested, however, reveals an apparent change in velocity dependence to smaller powers of Mach number. This change is believed to be (at least partly) due to increased scattering from the increased flow speed, which leads to stronger decorrelation effects and spectral levels from the array that are too low and/or decrease too rapidly with frequency. The presence of decorrelation effects was substantiated by comparison of microphone phased array measurements with single microphone measurements. These effects were, however, mitigated for part of the results shown by "isolating" the noise sources of interest through background noise subtraction, and by configuring the model such that only certain noise components were present. Finally, data acquired from the overhead and sideline microphones at different streamwise stations in the test section are used to obtain additional directivity information from the landing gear components. Noise directivity maps for the port main gear as well as for the full landing gear system are provided for a broad range of observer locations.

\section{Acknowledgments}

The authors would like to acknowledge the invaluable support provided by the 14- by 22-Foot Subsonic Tunnel team and by their colleagues in the Aeroacoustics and Advanced Sensing \& Optical Measurement branches who contributed to the realization and completion of the N2A-EXTE HWB aeroacoustic test as well as to the processing of the test data. Funding from the NASA Environmentally Responsible Aviation Project is also gratefully acknowledged.

\section{$\underline{\text { References }}$}

1. Kawai, R. T., "Acoustic Prediction Methodology and Test Validation for an Efficient Low-Noise Hybrid Wing Body Subsonic Transport,” Final report for NASA Contract Number NNL07AA54C, Feb. 2011.

2. Collier, F. S., "Environmentally Responsible Aviation (ERA) Project," Oral presentation, NASA Fundamental Aeronautics Program, Third Annual Meeting, Atlanta, GA, September 2009.

3. Gatlin, G. M., Vicroy, D. D., and Carter, M. B., "Experimental Investigation of the Low Speed Aerodynamic Characteristics of a 5.8-percent Scale Hybrid Wing Body Configuration," AIAA paper 2012-2669, 30 ${ }^{\text {th }}$ AIAA Applied Aerodynamics Conference, New Orleans, LA, June 2012.

4. Burley, C. L., Brooks, T. F., Hutcheson, F. V., Doty, M. J., Lopes, L. V., Nickol, C. L., Vicroy, D. D., Pope, D. S., "Noise Scaling and Community Noise Metrics for the Hybrid Wing Body Aircraft," AIAA paper 2014-2626, 20th AIAA/CEAS Aeroacoustics Conference in Atlanta, GA, June 16-20, 2014.

5. Hutcheson, F. V., "Overview of the Hybrid Wing Body Aeroacoustic Test in NASA Langley 14- by 22-Foot Subsonic Tunnel," Oral presentation, 20 ${ }^{\text {th }}$ AIAA/CEAS Aeroacoustics Conference in Atlanta, GA, June 16-20, 2014.

6. Hutcheson, F. V., Brooks, T. F., Burley, C. L., Bahr, C. J., Pope, D. S., "Shielding of Turbomachinery Broadband Noise from a Hybrid Wing Body Aircraft Configuration," AIAA paper 2014-2624, 20th AIAA/CEAS Aeroacoustics Conference in Atlanta, GA, June 16-20, 2014.

7. Doty, M. J., Brooks, T. F., Burley, C. L., Bahr, C. J., Pope, D. S., “Jet Noise Shielding Provided by a Hybrid Wing Body Aircraft," AIAA paper 2014-2625 , 20th AIAA/CEAS Aeroacoustics Conference in Atlanta, GA, June 16-20, 2014.

8. Heath, S. L., Brooks, T. F., Hutcheson, F. V., Doty, M. J., Haskin, H. H., Spalt, T. B., Bahr, C. J., Burley, C. L., Bartram, S. M., Humphreys, W. M., Jr., Lunsford, C. B., Popernack, T. G., Colbert, S.E., Hoad, D. R., Becker, L. E., Stead, D. J., Kuchta, D., and Yeh, L., "Hybrid Wing Body Aircraft Acoustic Test Preparations and Facility 
Upgrades," AIAA paper 2013-2623, 28th AIAA Aerodynamic Measurement Technology, Ground Testing, and Flight Testing Conference, June 2013, San Diego, CA.

9. Humphreys, W. M., Brooks, T. F., Bahr, C. J., Spalt, T. B., Bartram, S., Culliton, W. G., Becker, L. E., "Development of a Microphone Phased Array Capability for the 14- 22-foot Subsonic Tunnel," AIAA paper 2014-2343, 20th AIAA/CEAS Aeroacoustics Conference in Atlanta, GA, June 16-20, 2014.

10. Amiet, R. K.," Refraction of Sound by a Shear layer," Journal of Sound and Vibration, Vol. 58 (3), pp. 467-482, Sept. 1978.

11. Bahr, C. J., Brooks, T. F., Humphreys, W. M., Spalt, T. B., “Acoustic Data Processing and Transient Signal Analysis for the Hybrid Wing Body 14- by 22-Foot Subsonic Wind Tunnel Test," AIAA paper 2014-2345, 20th AIAA/CEAS Aeroacoustics Conference in Atlanta, GA, June 16-20, 2014.

12. Brooks, T. F., and Humphreys, W. M., Jr., "A Deconvolution Approach for the Mapping of Acoustic Sources (DAMAS) Determined from Phased Microphone Arrays," Journal of Sound and Vibration, Volume 294, pp. 856$879,2006$.

13. Brooks, T. F., Humphreys, W. M., Jr., Plassman, G. E., "DAMAS Processing for a Phased Array Study in the NASA Langley Jet Noise Laboratory," AIAA paper 2010-3780, 16th AIAA/CEAS Aeroacoustics Conference, Stockholm, Sweden, June 7-9, 2010.

14. Brooks, T. F. and Humphreys, W. M., Jr., "Effect of Directional Array Size on the Measurement of Airframe Noise Components," AIAA paper 99-1958, 5th AIAA/CEAS Aeroacoustics Conference, Bellevue, Washington, May $10-12,1999$.

15. Dougherty, R. P., "Turbulent Decorrelation of Aeroacoustic Phased Arrays: Lessons from Atmospheric Science and Astronomy," AIAA paper 2003-3200, 9 ${ }^{\text {th }}$ AIAA/CEAS Aeroacoustics Conference, Hilton Head, South Carolina, May $12-14,2003$.

16. Brooks, T. F., Pope, D. S. and Marcolini, M. A., “Airfoil Self-Noise and Prediction," NASA Reference Publication 1218, July 1989.

17. Humphreys, W. M., Jr., and Brooks, T. F., "Noise Spectra and Directivity For a Scale-Model Landing Gear," AIAA paper 2007-3458, $13^{\text {th }}$ AIAA/CEAS Aeroacoustics Conference, Rome, Italy, May 21-23, 2007.

18. Dobrzynski, W., Chow, L. C., Guion, P., and Shiells, D., “A European Study on Landing Gear Airframe Noise Sources," AIAA Paper 2000-1971, 6 ${ }^{\text {th }}$ AIAA/CEAS Aeroacoustics Conference, Lahaina, HI, 2000.

19. Brooks, T. F., and Humphreys, W. M., Jr., "Flap-edge aeroacoustic measurements and predictions," Journal of Sound and Vibration, Volume 261, pp. 31-74, 2003.

20. Hutcheson, F. V., Brooks, T. F. and Humphreys, W. M., Jr., "Noise Radiation from a Continuous Mold-Line Link Flap Configuration,” AIAA paper 2008-2966, Vancouver, Canada, May 5-8, 2008.

21. Schlinker, R. H., and Amiet, R. K., "Shear Layer Refraction and Scattering of Sound," AIAA Paper 80-973, 1980.

22. Zawodny, N. S., Liu, F., Yardibi, T., Cattafesta, L., Khorrami, M. R., Neuhart, D. H., Van de Ven, T., “A Comparative Study of a 1/4-scale Gulfstream G550 Aircraft Nose Gear Model," AIAA paper 2009-3153, 15 AIAA/CEAS Aeroacoustics Conference, Miami, FL., May 11-13, 2009.

23. Khorrami, M. R., Lockard, D. P., Humphreys, W. M., Jr., Choudhari, M. M., and Van de Ven, T., "Preliminary Analysis of Acoustic Measurements from the NASA-Gulfstream Airframe Noise Flight Test," AIAA Paper 20082814, 14 ${ }^{\text {th }}$ AIAA/CEAS Aeroacoustics Conference, Vancouver, Canada, May 5-7, 2008.

24. Spalart, P. R., "On the precise implications of acoustic analogies for aerodynamic noise at low Mach numbers," Journal of Sound and Vibration, Vol. 332, pp. 2808-2815, 2013. 